\title{
Synthesis of carbon-supported bimetallic palladium- iridium catalysts by microemulsion: characterization and electrocatalytic properties
}

\author{
Tomasz Szumełda $^{1}$ (D), Alicja Drelinkiewicz ${ }^{1, *}$ (D), Robert Kosydar ${ }^{1}$ (D), Jacek Gurgul ${ }^{1}$ (D), \\ and Dorota Duraczyńska ${ }^{1}$ (D) \\ ${ }^{1}$ Jerzy Haber Institute of Catalysis and Surface Chemistry, Polish Academy of Sciences, Niezapominajek 8, 30239 Krakœw, Poland
}

Received: 28 February 2020

Accepted: 26 August 2020

Published online:

17 September 2020

(C) The Author(s) 2020

\begin{abstract}
Carbon (Vulcan XC-72)-supported bimetallic Pd-Ir catalysts with different Pd/ Ir proportions (5-50 mol\% Ir, 2 wt $\%$ Pd) were prepared by "water-in-oil" microemulsion method (w/o) using solutions of low (0.02 M, L series) and high concentration $\left(0.2 \mathrm{M}, \mathrm{H}\right.$ series) of the metals precursors $\left(\mathrm{PdCl}_{2}\right.$ and $\left.\mathrm{IrCl}_{3}\right)$. The bimetallic particles were examined in terms of nanoscale phase properties (extent of Pd-Ir alloying, phase separation), surface composition (Pd and Ir fractions) and electrocatalytic performance for the formic acid oxidation reaction. Structural characterization was performed using XRD, SEM and HRTEM techniques. Electrochemical characterization allowed estimating the $\mathrm{PdH}$ formation ability and the surface composition of Pd-Ir particles what was confirmed by XPS data. The Pd-Ir nanoparticles of similar average size (ca. $4 \mathrm{~nm}$ ), close to that of $\mathrm{Ir}(3.8 \mathrm{~nm})$ and below that of $\mathrm{Pd}(6.2 \mathrm{~nm})$ were formed regardless of the $\mathrm{Pd} / \mathrm{Ir}$ proportion and the concentration of the metals precursors in the w/o. In contrast to the largely alloyed PdIr nanoparticles with the Pd-rich surface formed at low concentration of the metals precursors $(0.02 \mathrm{M})$, the particles of almost closed surface and bulk $\mathrm{Pd} / \mathrm{Ir}$ ratios composed mostly of randomly distributed single-phase domains were formed at high concentration $(0.2 \mathrm{M})$. At the lowest bulk Ir content, $5 \mathrm{~mol} \%$, the particles have Ir-rich surface regardless of the preparation method. The catalytic studies involving formic acid electrooxidation reaction showed the activity enhancement for the $L$ series catalysts with respect to monometallic $\mathrm{Pd} / \mathrm{C}$ (twofold TOF increase) and $\mathrm{H}$ series counterparts. The $\mathrm{Pd}_{85} \mathrm{Ir}_{15} / \mathrm{C}$ catalyst of the Pd-Ir alloyed and the surface composition expressed by the $\mathrm{Pd} / \mathrm{Ir}$ atomic ratio near to 6 displayed the highest activity which was 2.9times higher relative to that of $\mathrm{Pd}$.
\end{abstract}

Handling Editor: N. Ravishankar.

Address correspondence to E-mail: ncdrelin@cyf-kr.edu.pl 


\section{GRAPHIC ABSTRACT}

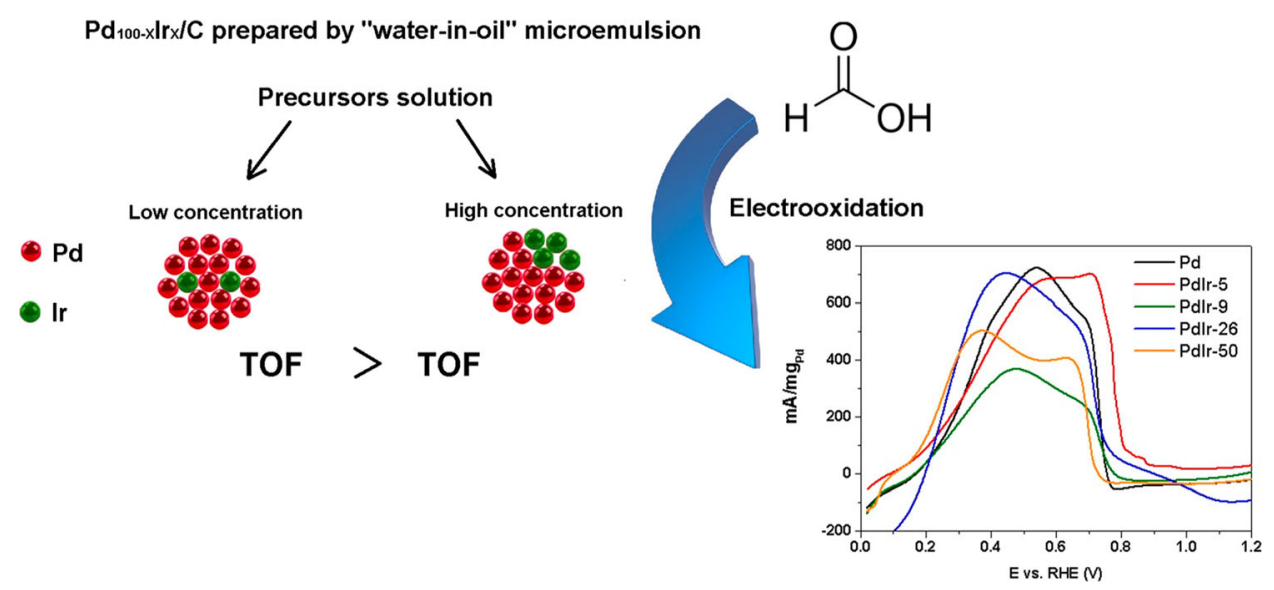

\section{Introduction}

Most of the literature studies on bimetallic systems preparation have focused on the traditional co-impregnation/reduction method. Such a procedure usually results in a poor control over the particles size, shape and nanoscale phase structures of the particles, surface segregation of the components and alloying degree or atomic distribution, while these properties are of crucial importance in determining the catalytic properties of bimetallic systems. The colloidal techniques have been reported to be more advantageous as they allowed for synthesis of sizeand structure-controlled metal nanoparticles of almost uniform size. Steric stabilizers like polyvinylpyrrolidone (PVP) are usually used during the synthesis in order to protect nanoparticles from the excessive growth. The colloidal strategy was found to be effective in the synthesis of alloy nanoparticles of metals with miscibility gap in bulkscale systems like $\mathrm{Au}-\mathrm{Rh}, \mathrm{Au}-\mathrm{Pt}, \mathrm{Pt}-\mathrm{Rh}, \mathrm{Pd}-\mathrm{Rh}$ [1-3]

The $\mathrm{Au}-\mathrm{Rh}$ alloy nanoparticles over the entire composition range across the miscibility gap were synthesized by the room-temperature borohydride co-reduction of aqueous metal salts solutions in the presence of variety of surface stabilizers (polyvinyl alcohol, polyvinylpyrrolidone, citrate, CTAB) [3]. The formation of alloy nanostructures has been related to the fact that the reduction of the metals ions in the confined spaces (within micelles) facilitated co-nucleation via spatial sequestration [1-3].

In the case of completely immiscible $\mathrm{Au}$ and $\mathrm{Rh}$ metals, the nanostructures of a different segregation ranging from $\mathrm{Au}$ (core)-Rh(shell) to alloyed $\mathrm{AuRh}$ were identified $[1,3,4]$. Both the complex deposition and the growth pattern of these nanostructures driven by the reaction kinetics have been invoked to explain the formation of these structures by colloidal chemical reduction [4].

The colloid-based preparation method, namely a reverse "water-in-oil" microemulsion (w/o), was also reported to be effective in the synthesis of alloyed nanoparticles such as $\mathrm{Pd}-\mathrm{Pt}, \mathrm{Pd}-\mathrm{Au}, \mathrm{Pt}-\mathrm{Au}, \mathrm{Pd}-\mathrm{Ni}$, $\mathrm{C}-\mathrm{Ni}$ and $\mathrm{Au}-\mathrm{Ag}$ [5]. In w/o method, all processes including the chemical reduction of metal ions, nucleation and growth of the metal particles take place within the confined space of aqueous droplets dispersed in a continuous oil phase stabilized by surfactant molecules $[6,7]$. These conditions provide an easy control of the particle size and allow the synthesis of uniformly dispersed metal particles characterizing by uniformity of their surface properties. By adjusting the preparation conditions (metal ions concentration, the type of surfactant and reducing agent, etc.) or varying the size of the inverse micelles by changing the water-to-surfactant molar ratio (" $w$ " parameter), the metal particle size and the size distribution can be experimentally controlled.

According to the molecular dynamic simulations $[5,8-10]$, if the reduction of the metal ions is 
instantaneous, as when reducing agent is directly added to the micellar system containing metal precursors, the formation of metal particles is governed by the nucleation processes. As a result, the bimetallic particles of uniform size are formed. They are smaller than the size of monometallic counterparts what was observed for $\mathrm{Pd}-\mathrm{Ag}, \mathrm{Pd}-\mathrm{Au}, \mathrm{Pt}-\mathrm{Au}$ and $\mathrm{Pd}-\mathrm{Pt}$ particles [11-14]. Furthermore, the difference in the nucleation rates of the metal components is a key factor determining the segregation of the metals throughout the particle. The metal with the fastest nucleation rate will give rise to the majority of seeds. They will grow building a core, on which the slower metal is deposited. For instance, since the nucleation rate of $\mathrm{Au}$ was much faster than that of $\mathrm{Ag}, \mathrm{Au}$ played a seeding role in the $\mathrm{Au}-\mathrm{Ag}$ particles formation giving Au-enriched core and Ag-enriched surface [11]. Much faster nucleation rate of Au compared to that of $\mathrm{Pd}$ provided the $\mathrm{Pd}-\mathrm{Au}$ clusters with the surface enriched in Pd [12]. The nucleation rates of metals are directly related to the size of critical nucleus. As the critical nucleus is smaller, the nucleation rate is faster and the particles of smaller size are formed. The hypothesis that the size of the critical nucleus depends on the strength of the metalmetal bond has been formulated [15]. More specifically, a metal with higher bond strength, as reflected by a higher heat of metal vaporization $\Delta H_{\mathrm{VAP}}$ (or sublimation, $\Delta H_{\mathrm{S}}$ ), should result in a smaller nanocluster. This hypothesis was confirmed by the proportional growth of the particles size as the $\mathrm{H}_{\mathrm{VAP}}$ increases from Os and Ir through $\mathrm{Pt}$ and $\mathrm{Rh}$ to $\mathrm{Pd}$ [15]. Similar metal-type relation was also reported in our previous work dealing with the formation of monometallic Ir, Ru, Pt, Pd and Au colloidal particles by the microemulsion procedure [16].

Furthermore, according to the simulation results, the structure of bimetallic nanoclusters should be related to the difference between the homogeneous nucleation rates of the metals $(\mathrm{A}, \mathrm{B})$ and the rate of co-nucleation $(\mathrm{AB})[9,10]$. Faster process of the heterogeneous nuclei formation compared to homogeneous nucleation favors metals alloying in the final particle. This implies the influence of the concentration of the metals precursors on the nanostructure of the particles $[5,10,17,18]$. The molecular dynamic simulations demonstrated that the low concentration of metals precursors promoted core-shell structure formation with core enriched in the metal of smaller nucleus size [10]. The extent of metal segregation was weaker at high concentration of the metals precursor which increased the possibility of the alloyed structure formation. This theoretical prediction was confirmed by the $\mathrm{Pt}-\mathrm{Au}$ particles formation [17]. In the diluted precursors solution, the particles with the core enriched in $\mathrm{Au}$ (metal of higher nucleation rate) covered by a $\mathrm{Pt}-\mathrm{Au}$ mixed shell were formed. The particles synthesized at high concentration of the metals precursors displayed more homogeneous $\mathrm{Pt}$ and $\mathrm{Au}$ concentration profiles from the outer shell to the core.

However, the sequence of metal components deposition could be also determined by difference in the reduction potentials $[5,19,20]$. The metal ion which reduces faster forms the nucleus and locates in the core, while the "slower" one locates in the outer shell of the particle. Thus, a large difference in the reduction potential will promote "core-shell" structures.

The bulk Pd and Ir metals are characterized by a broad miscibility gap [21]. At temperatures up to $750{ }^{\circ} \mathrm{C}$, only $3 \%$ Ir is soluble in Pd. At higher temperatures in the entire range of $\mathrm{Pd}$ and Ir composition, a series of completely miscible solid solutions based on the face-centered cubic (fcc) lattice is formed [21-23]. A miscibility of $\mathrm{Pd} / \mathrm{Ir}$ was enhanced at the nanoscale, and the ca. $2 \mathrm{~nm}$-sized alloyed PdIr clusters were formed [24, 25].

The DFT studies dealing with the phase properties of the Pd-Ir clusters of different compositions (Pd/Ir proportion) and morphologies such as mixed (ordered alloy), core-shell, Janus-type and ball-cup found that the $\operatorname{Ir}$ (core)-Pd(shell) configuration is the most stable at small Ir content [26]. These findings are consistent with the higher cohesive and surface energies of Ir when compared with Pd in bulk state. Stability of the $\operatorname{Ir}$ (core)-Pd(shell) configuration decreases with growing Ir content at the expense of other structures, such as ball-cup, Janus-type and ordered one, which was found to be much less stable attributed to higher strength of the Ir-Ir bond relative to that of Pd-Pd [26].

The systematic studies showed the surface enrichment in Pd in the case of bulk Pd-Ir alloys, irrespective of the Ir content [27]. Similar Pd-enriched surface was observed by Schwarz et al. [28] in the thin film of $\mathrm{Pd}_{75} \mathrm{Ir}_{25}$ and $\mathrm{Pd}_{25} \mathrm{Ir}_{75}$ compositions. The Pd surface enrichment in these Pd-Ir bulk systems was also attributed to the higher surface energy of Ir $\left(3.05 \mathrm{~J} / \mathrm{m}^{2}\right)$ than that of $\mathrm{Pd}\left(2.05 \mathrm{~J} / \mathrm{m}^{2}\right)$. Moreover, the 
Pd-Ir couple has a large difference in reduction potential $(\Delta \varepsilon=0.71 \mathrm{~V})$ as Ir has higher reduction potential $\left(\mathrm{Ir}^{3+} / \mathrm{Ir}=1.19 \mathrm{~V}\right)$ compared to that of $\mathrm{Pd}$ $\left(\mathrm{Pd}^{2+} / \mathrm{Pd}=0.48 \mathrm{~V}\right)$. In view of the above described general principle, i.e., a component with lower surface energy and/or lower reduction potential tends to be concentrated on the surface, the particles of a quasi core-shell structures with Pd enriched in surface would be likely formed.

In the present work, we focus on the synthesis of the PdIr nanoparticles by means of microemulsion procedure. As far as we known, no systematic research was reported dealing with the employing of microemulsion method for the Pd-Ir nanoparticles. Here, the nanostructure of the synthesized bimetallic PdIr particles of various $\mathrm{Pd} / \mathrm{Ir}$ proportions is studied and correlated with their catalytic reactivity for the formic acid (FA) electrooxidation reaction.

The formic acid (FA) electrocatalytic oxidation reaction has a great potential as an "in situ" hydrogen source in the membrane fuel cells technology. Moreover, the Pd catalysts and specifically the Pdbased bimetallic catalysts including also the $\mathrm{Pd}-\mathrm{Ir}$ system have been recognized to be preferred for the FA electrooxidation reaction [29]. It should be noted that the addition of Ir to Pd promoted the electroactivity also in electrooxidation of ethanol [30, 31], methanol and ethylene glycol [32]. However, as the surface composition was not controlled and/or known, the changes in catalytic behavior were typically assigned to synergy between Pd and Ir which manifested at a certain $\mathrm{Pd} / \mathrm{Ir}$ proportion. For instance, in the FA electrooxidation reaction a synergy corresponding to the $\mathrm{Pd} / \mathrm{Ir}$ atomic ratio of $5 / 1$ was observed by Wang et al. [33], while the composition with lower Ir content, corresponding to the $\mathrm{Pd} /$ Ir $=9 / 1$ has been reported by Chen et al. [34]. These optimum Pd/Ir molar ratios corresponded to the 1.3and 1.6-fold increase in the Pd-mass activity for FA relative to pure $\mathrm{Pd}$, respectively. In the former case, the catalysts were prepared by co-impregnation followed by $\mathrm{NaBH}_{4}$ reduction. In the latter, the ethylene glycol-assisted $\mathrm{NaBH}_{4}$ reduction was applied. On the other hand, Adams et al. [35] observed that nanoporous Pd-Ir film of low Ir content, $10 \mathrm{~mol} \%$, displayed only slightly higher FA electroactivity compared to pure Pd. However, very high electroactivity surpassing more than three times that of pure Pd has been reported for the catalyst consisting of "islands-like Pd domains" deposited onto the preformed $\mathrm{Ir} / \mathrm{C}$ catalyst with $\mathrm{Pd} / \mathrm{Ir}$ atomic ratio of $7 / 3$ [36].

Here, two series of carbon-supported $\mathrm{Pd}_{100-x} \mathrm{Ir}_{x} / \mathrm{C}$ catalysts with Ir content ranging from 5 to $50 \mathrm{~mol} \%$ are prepared using low (0.02 M, L series) and high (0.2 M, H series) concentrations of the metals precursors $\left(\mathrm{PdCl}_{2}+\mathrm{IrCl}_{3}\right)$. The synthesized $\mathrm{PdIr} / \mathrm{C}$ catalysts are examined in terms of nanoscale phase properties (extent of $\mathrm{Pd}-\mathrm{Ir}$ alloying, phase separation), surface composition (fraction of Pd and Ir) and electrocatalytic properties. The structural characteristics are determined by XRD and electron microscopy (SEM, HRTEM) techniques. XPS provided information about the composition and electronic structure of the surface. Additional data about the structure of bimetallic particles were obtained by cyclic voltammetry measurements $(\mathrm{CV})$.

The FA electrooxidation activities of $\mathrm{L}$ and $\mathrm{H}$ series bimetallic PdIr/C catalysts are compared to each other and to that of monometallic $\mathrm{Pd} / \mathrm{C}$ with the aim of assessing the impact of the particles nanostructure on the catalytic properties.

\section{Experimental}

\section{Catalysts synthesis}

Carbon (Vulcan XC-72, Cabot) was used as the support. The catalysts were prepared by means of reverse "water-in-oil" (w/o) microemulsion method as previously reported $[16,37,38]$. The catalysts were synthesized to have Pd loading of $2 \mathrm{wt} \%$, whereas the Ir content grows from $5 \mathrm{~mol} \%$ (PdIr-5) to $50 \mathrm{~mol} \%$ (PdIr-50). Two series of catalysts of the same Pd/Ir molar ratios were prepared. The one, abbreviated as "L," covers the PdIr/C catalysts prepared using precursor solutions of low concentration $(0.02 \mathrm{~mol} /$ $\mathrm{dm}^{3} \mathrm{PdCl}_{2}$ and $\mathrm{IrCl}_{3}$ ). In the second series abbreviated as " $\mathrm{H}$," the precursor solutions of 10-times higher $\left(0.2 \mathrm{~mol} / \mathrm{dm}^{3}\right)$ concentration were used. The monometallic catalysts, $2 \mathrm{wt} \% \mathrm{Pd} / \mathrm{C}$ and $2 \mathrm{wt} \% \mathrm{Ir} / \mathrm{C}$, were prepared under conditions corresponding to $\mathrm{H}$ series.

Shortly, the microemulsion was prepared using polyoxyethylene(7-8)octylphenyl ether (Triton X-114, Aldrich) as the surfactant and cyclohexane (Aldrich) as the oil phase. In all syntheses, the same value of " $\mathrm{w}$ " parameter (molar ratio of water to surfactant) equal to 5.5 was applied. The aqueous solutions of 
$\mathrm{PdCl}_{2}$ (Johnson Matthey; molar ratio of $\mathrm{NaCl}: \mathrm{PdCl}_{2}=$ 2, $\mathrm{Pd}^{2+}$ ions concentration of 0.2 or $0.02 \mathrm{~mol} / \mathrm{dm}^{3}$ ) and $\mathrm{IrCl}_{3}$ (Aldrich; 0.2 or $0.02 \mathrm{~mol} / \mathrm{dm}^{3}$ ) were used as the precursors. $\mathrm{NaBH}_{4}$ (Aldrich) powder was used as a reducing agent (molar ratio of $\mathrm{NaBH}_{4} /$ metal ions of 20). In order to prepare $1 \mathrm{~g}$ of $2 \mathrm{wt} \% \mathrm{Pd} / \mathrm{C}$ catalyst, $0.94 \mathrm{~cm}^{3}$ of $\mathrm{PdCl}_{2}$ solution was added to $16.8 \mathrm{~cm}^{3}$ of cyclohexane solution of surfactant (surfactant concentration of $0.62 \mathrm{~mol} / \mathrm{dm}^{3}$ ) and vigorously stirred up to the formation of transparent, clear dark orange liquid. During the preparation of PdIr catalysts, a mixture of $\mathrm{PdCl}_{2}$ and $\mathrm{IrCl}_{3}$ solutions with the appropriate volume ratio and the cyclohexane solution with the surfactant concentration giving the $w=$ 5.5 was used. The reducing agent $\left(\mathrm{NaBH}_{4}\right)$ was added directly to the metal ions-containing microemulsion, and the color of the liquid changed from yellow to black. Stirring was maintained for $1 \mathrm{~h}$. Then, the carbon support $(0.98 \mathrm{~g})$ was added and stirring continued for the additional $1 \mathrm{~h}$. The deposition of metal nanoparticles on the support was carried out by slow introducing of THF solvent with a syringe pump under vigorous stirring. Upon the addition of THF, the color of liquid gradually changed from black to grey and finally, the liquid was colorless, proving the complete particles deposition on the support. The catalyst was separated by filtration, dried in air for $24 \mathrm{~h}$ and washed with copious amount of methanol, acetone and water to remove surfactant and chloride ions and finally dried for $16 \mathrm{~h}$ at $120{ }^{\circ} \mathrm{C}$.

\section{Methods of characterization}

The X-ray diffraction (XRD) patterns were obtained with a Philips X'PERT diffractometer using $\mathrm{Cu} \mathrm{Ka}$ radiation. The average diameter of $\mathrm{Pd}$ particles was calculated on the basis of the Pd ( $\left.\begin{array}{lll}1 & 1 & 1\end{array}\right)$ peak broadening according to Scherrer equation taking into account instrumental broadening.

The X-ray photoelectron spectroscopy (XPS) measurements were carried out with a hemispherical analyzer (SES R4000, Gammadata Scienta). The unmonochromatized $\mathrm{Mg} \mathrm{K \alpha}$ X-ray source was applied to generate core excitation. The samples were pressed into indium foil. All spectra were collected at pass energy of $100 \mathrm{eV}$ except the survey scans which were collected at pass energy of $200 \mathrm{eV}$. Intensities were estimated by calculating the integral of each peak, after subtraction of the Shirley-type background, and fitting the experimental curve with a combination of Gaussian and Lorentzian lines of variable proportions (70:30).

Scanning electron microscopy (SEM) studies were performed by means of Field Emission Scanning Electron Microscope JEOL JSM 7500 F equipped with the energy-dispersive X-ray spectroscopy (EDS) system. Two detectors were used for recording the images. The secondary electron detector provided SEI images, and the backscattered electron detector (sensitive for mass contrast) provided COMPO micrographs. To prepare the particle size distribution diagram and to estimate the average particle size (d), at least 100 particles $(\mathrm{N})$ were manually counted. The counting was carried out on electron micrographs registered at magnifications of 100000-200000, where metal particles contrasted well with the carbon support. On these micrographs registered in COMPO mode, the accuracy of the particle size scale was $0.5 \mathrm{~nm}$.

Transmission electron microscopy (HRTEM and STEM) studies were performed on FEI Tecnai $G^{2}$ transmission electron microscope equipped with EDS and HAADF/STEM detectors. Samples for analysis were placed onto a carbon-coated copper grid. The local composition of the metal particles was determined by EDS where the composition of individual particles could be measured.

The metal dispersion $(D)$ in catalysts was calculated using formula (1) [37]:

$D=\frac{6 \cdot n_{\mathrm{s}} \cdot M}{\rho \cdot N_{\mathrm{A}} \cdot d_{\mathrm{av}}}$

where $n_{\mathrm{s}}$ is the number of atoms at the surface per unit area $\left(n_{\mathrm{s}}(\mathrm{Pd})=1.27 \times 10^{19} \mathrm{~m}^{-2}, \quad n_{\mathrm{s}}(\mathrm{Ir})=1.30 \times\right.$ $\left.10^{19} \mathrm{~m}^{-2}\right), M$ is the molecular weight, $\mathrm{N}_{\mathrm{A}}=6.023 \times$ $10^{23} \mathrm{~mol}^{-1}, \rho$ is the density, $\rho_{\mathrm{Pd}}=1.20 \times 10^{7} \mathrm{~g} / \mathrm{m}^{3}, \rho_{\mathrm{Ir}}=$ $2.26 \times 10^{7} \mathrm{~g} / \mathrm{m}^{3}$, and $d_{\mathrm{AV}}$ is the average particle size measured by XRD/SEM.

For the bimetallic catalysts, the average numbers of the parameters $n_{\mathrm{s}}$ and $\rho$ were calculated considering the actual $\mathrm{Pd} / \mathrm{Ir}$ composition.

Electrochemical measurements were performed in a conventional three-electrode electrochemical cell using a $\mathrm{CH}$ Instrument (Austin, USA) Model 760D workstation. A graphite rod and a mercury/mercury sulfate electrode $\left(\mathrm{Hg} / \mathrm{Hg}_{2} \mathrm{SO}_{4}, 0.718 \mathrm{~V}\right.$ vs. reversible hydrogen electrode) were used as the counter electrode and the reference electrode, respectively [39]. A glassy carbon disk electrode (GC) (2.805 mm radius, 
geometric area, $0.247 \mathrm{~cm}^{2}$ ) coated with a layer of catalysts ink was used as the working electrode. The ink of the catalysts was prepared by ultrasonically mixing of $5 \mathrm{mg}$ of catalyst sample with $0.029 \mathrm{~cm}^{3}$ of Nafion (5 wt\% in lower aliphatic alcohols and water, Aldrich) in $1 \mathrm{~cm}^{3}$ of 2-propanol (Avantor). $13.3 \mu \mathrm{l}$ of the suspension was introduced onto the GC electrode and left to dry (30 min, room temperature). It corresponds to a constant Pd loading on the electrode $\left(10 \mu \mathrm{g} / \mathrm{cm}^{2}\right)$. The measurements were performed at room temperature and ambient pressure in an $\mathrm{Ar}$ deoxygenated $0.5 \mathrm{M}$ sulfuric acid solution at a scan rate of $50 \mathrm{mV} / \mathrm{s}$. Formic acid electrooxidation was studied in $0.5 \mathrm{M}$ sulfuric acid solution containing $0.5 \mathrm{M}$ formic acid (Aldrich) [39]. The potentials values given in the text are referred to the reversible hydrogen electrode (RHE). By considering the potential zone of surface oxide reduction peak, the electrochemically active surface area (EASA) was estimated using the relation $E A S A=Q / S$, where $Q$ is the observed Coulombic charge $(\mathrm{mC})$ and $S$ is the proportionality factor, $0.428 \mathrm{mC} / \mathrm{cm}^{2}$, corresponding to the reduction of $\mathrm{PdO}$.

\section{Results and discussion}

\section{Characterization of catalysts}

The XRD pattern of carbon Vulcan XC-72 shows a broad intense reflection around $2 \theta=25^{\circ}$ and a smaller one around $2 \theta=43^{\circ}$ (Fig. 1). The first corresponds to the graphite (002) crystallographic plane of carbon (XRD reference code ICDD PDF 98-002-8419), and the second corresponds to the (111) plane of diamond
(XRD reference code ICDD PDF 98-004-4101) [40]. In order to make easier observation of the Pd/Ir-arising reflections, the magnified $2 \theta$ range of the $\left(\begin{array}{lll}1 & 1 & 1\end{array}\right)$ diffraction peaks is displayed in Fig. 2

Both crystalline metals Pd and Ir are characterized by a face-centered cubic (fcc) structure, and the $d$ space of $\operatorname{Pd}\left(d_{111}=0.2246 \mathrm{~nm}\right)$ is slightly higher compared to that of Ir $\left(d_{111}=0.2217 \mathrm{~nm}\right)$. The reflections at $2 \theta=40.1^{\circ}\left(\begin{array}{lll}1 & 1 & 1\end{array}\right)$ and $68.1^{\circ}(220)$ characteristic of crystalline Pd are visible in the pattern of $2 \% \mathrm{Pd} / \mathrm{C}$ catalyst, whereas no reflections of crystalline Ir are registered for the $2 \% \mathrm{Ir} / \mathrm{C}$ catalyst. This might be a result of an amorphous state or too small size of Ir crystallites, similarly to what was observed for the $2 \%$ $\mathrm{Ir} / \mathrm{SiO}_{2}$ catalyst with Ir particles of $2-4 \mathrm{~nm}$ [41]. The metal reflections in the XRD patterns of bimetallic PdIr/C catalysts are located at slightly higher $2 \theta$ values compared to those of Pd/C (Figs. 1, 2). This shows that the fcc crystalline structure is preserved in the bimetallic PdIr crystallites and some Ir atoms entered into the Pd lattice consistently with previous reports [30, 32, 41, 42]. In PdIr-0.05/C catalysts of L and $\mathrm{H}$ series with the smallest Ir content $(5 \mathrm{~mol} \%)$, no essential changes in the position of the $\left(\begin{array}{lll}1 & 1 & 1\end{array}\right)$ reflection relative to that of $\mathrm{Pd}$ can be seen. The shift to higher $2 \theta$ value manifests clearly at higher bulk Ir content in both series of catalysts. This implies contraction of the lattice due to intercalation of Ir. The lattice parameters of the PdIr crystallites are calculated to be between that of $\mathrm{Pd}(0.3905 \mathrm{~nm})$ and $\mathrm{Ir}$ $(0.384 \mathrm{~nm})$ (Table 1) in accordance with previous data for the PdIr in the supported [30, 31, 41], nanostructured [42] and bulk alloys [43]. A decrease in lattice
Figure 1 XRD patterns of $2 \mathrm{wt} \% \mathrm{Pd} / \mathrm{C}$ and $\mathrm{PdIr} / \mathrm{C}$ catalysts of $\mathbf{a} \mathrm{L}, \mathbf{b} \mathrm{H}$ series as well as carbon support; the positions of the most intense $\mathrm{X}$-ray diffraction lines characteristic for $\mathrm{IrO}_{2}$ (ICDD PDF 00-015-0870) and PdO (ICDD PDF 00-041-1107) are marked.
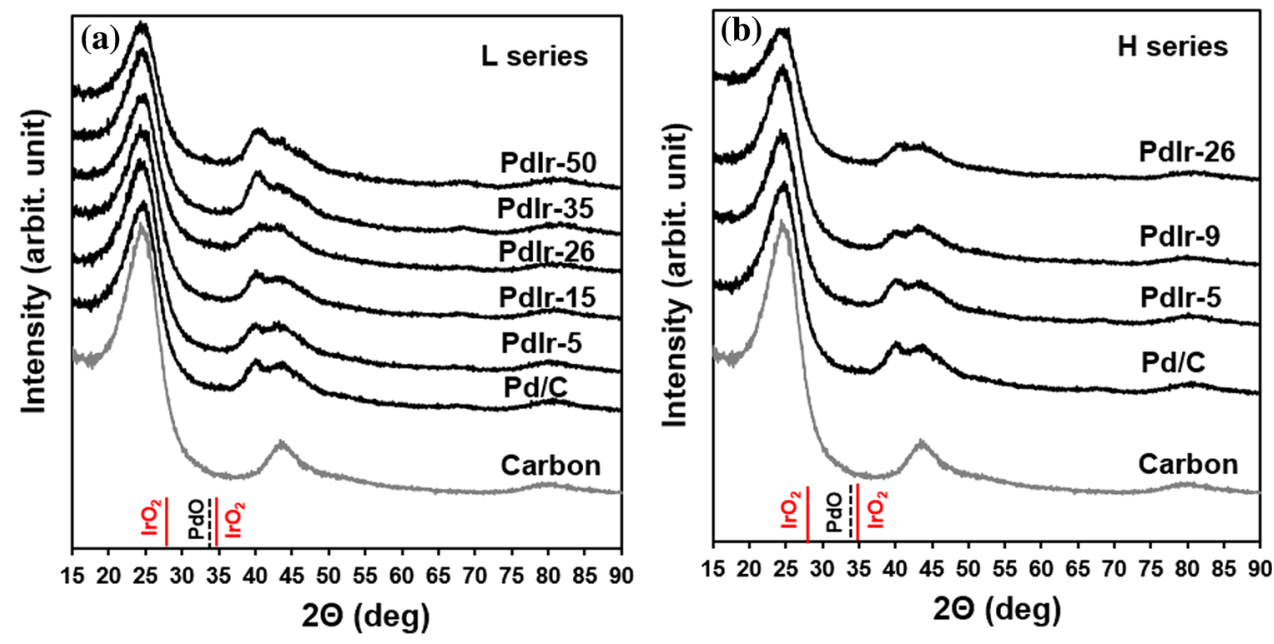
Figure 2 XRD patterns of $2 \mathrm{wt} \% \mathrm{Pd} / \mathrm{C}$ and $\mathrm{PdIr} / \mathrm{C}$ catalysts of $\mathbf{a} \mathrm{L}, \mathbf{b} \mathrm{H}$ series as well as carbon support; the positions of X-ray diffraction lines characteristic for metallic Ir are marked (ICDD PDF 00-046-1044).
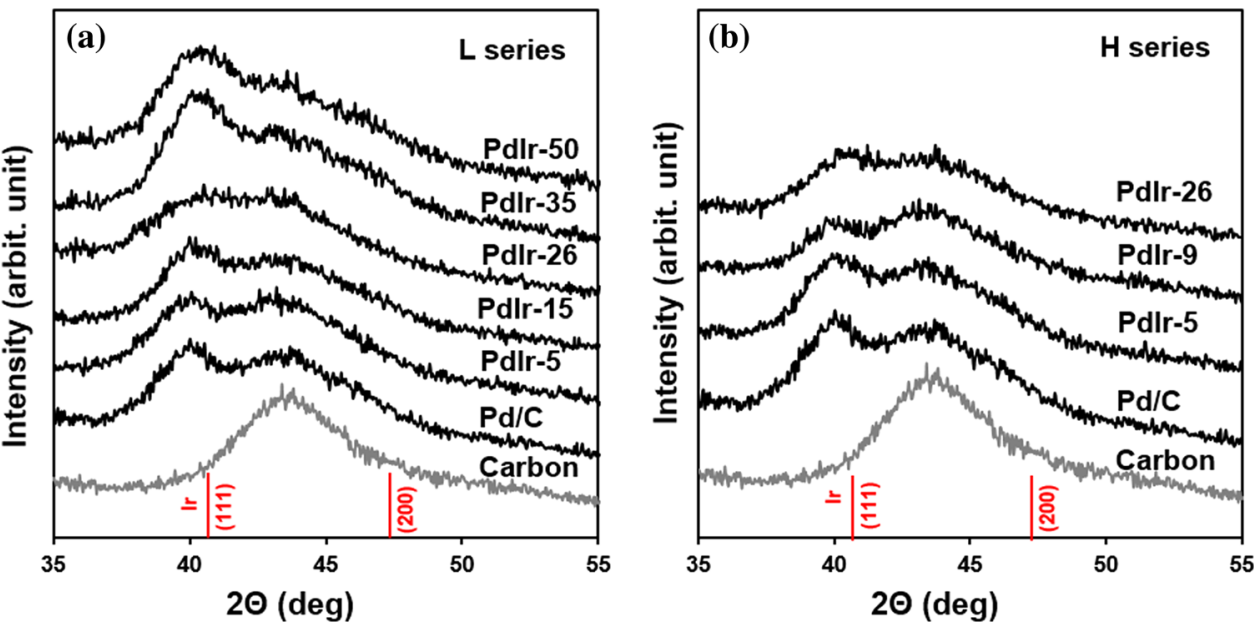

Table 1 Physicochemical properties of catalysts and the activity for formic acid electrooxidation

\begin{tabular}{|c|c|c|c|c|c|c|c|c|c|c|}
\hline \multirow[t]{2}{*}{ Catalyst } & & \multirow[t]{2}{*}{$d_{\mathrm{p}}(\mathrm{nm})$} & \multirow[t]{2}{*}{$a(\mathrm{~nm})$} & \multicolumn{2}{|c|}{$\mathrm{Pd} / \mathrm{Ir}$ atomic ratio } & \multirow[t]{2}{*}{$D(\%)$} & \multirow{2}{*}{$\begin{array}{l}E \\
(\mathrm{H})(\mathrm{V})\end{array}$} & \multirow[t]{2}{*}{$E_{\mathrm{P}} \mathrm{FA} \max$} & \multirow{2}{*}{$\begin{array}{l}\text { EASA } \\
\left(\mathrm{cm}^{2}\right)\end{array}$} & \multirow[t]{2}{*}{$\mathrm{TOF}\left(\mathrm{s}^{-1}\right)$ at $0.54 \mathrm{~V}$} \\
\hline & & & & EDS & STEM & & & & & \\
\hline $\mathrm{Pd}$ & $\mathrm{H}$ & 6.2 & 0.3905 & & & 18.7 & 0.167 & 0.541 & 0.38 & 11.36 \\
\hline PdIr-5 & $\mathrm{L}$ & 5 & & $93.9 / 6.1$ & & & 0.122 & 0.591 & 0.75 & 8.28 \\
\hline $\mathrm{Pd}_{95} \mathrm{Ir}_{5}$ & $\mathrm{H}$ & 4.8 & & $94.2 / 5.8$ & & 21.3 & 0.095 & 0.541 & 0.76 & 5.25 \\
\hline PdIr-9 & $\mathrm{L}$ & 4.2 & 0.3895 & $90.9 / 9.1$ & & 25.3 & 0.083 & 0.499 & 0.41 & 13.39 \\
\hline $\mathrm{Pd}_{91} \mathrm{Ir}_{9}$ & $\mathrm{H}$ & 4.3 & 0.3890 & $\begin{array}{l}\text { 93/7; } \\
89 / 11\end{array}$ & $85 / 15 ; 87 / 13$ & 24.7 & 0.070 & 0.478 & 0.19 & 11.03 \\
\hline $\begin{array}{l}\text { PdIr-15 } \\
\operatorname{Pd}_{85} \operatorname{Ir}_{15}\end{array}$ & $\mathrm{~L}$ & 4.8 & 0.3896 & $81.7 / 18.3$ & $\begin{array}{l}85 / 15 ; 81 / 19 \\
81 / 18\end{array}$ & 21.6 & 0.066 & 0.507 & 0.42 & 29.09 \\
\hline PdIr26 & $\mathrm{L}$ & 4.3 & 0.3885 & $77 / 23$ & $75 / 25$ & 23.2 & 0.055 & 0.413 & 0.52 & 16.31 \\
\hline $\mathrm{Pd}_{74} \mathrm{Ir}_{26}$ & $\mathrm{H}$ & 4.9 & 0.3884 & $78 / 22$ & $73 / 27$ & 20.3 & 0.078 & 0.444 & 0.54 & 12.71 \\
\hline PdIr-35 & $\mathrm{L}$ & 4.3 & 0.3882 & $66.6 / 33.4$ & & 23.0 & 0.083 & 0.469 & 0.66 & 15.04 \\
\hline $\mathrm{Pd}_{65} \mathrm{Ir}_{35}$ & & & & & & & & & & \\
\hline PdIr-50 & $\mathrm{L}$ & 3.5 & 0.3864 & $49 / 51$ & & 29.0 & 0.055 & 0.302 & 0.21 & 2.55 \\
\hline $\mathrm{Pd}_{50} \mathrm{Ir}_{50}$ & $\mathrm{H}$ & 3.8 & 0.3870 & $52.3 / 47.7$ & & 26.7 & 0.058 & 0.363 & 0.38 & 6.14 \\
\hline Ir & $\mathrm{H}$ & 3.8 & 0.3840 & & & & & & & \\
\hline
\end{tabular}

parameter with the growing Ir content in the $\mathrm{Pd}-\mathrm{Ir}$ system has also been theoretically predicted $[22,23]$.

The size of metal crystallites estimated by the Scherrer equation for ( $\left.\begin{array}{lll}1 & 1 & 1\end{array}\right)$ reflection broadening is summarized in Table 1 . The crystallites of Pd in the $2 \% \mathrm{Pd} / \mathrm{C}$ catalyst are calculated to be $6.2 \mathrm{~nm}$ in size. The Ir crystallites in the $2 \% \mathrm{Ir} / \mathrm{C}$ catalyst are much smaller, $3.8 \mathrm{~nm}$ in size. The bimetallic PdIr crystallites in both $\mathrm{L}$ and $\mathrm{H}$ series catalysts are of smaller size compared to pure Pd/C. They are of around 3.5$4.8 \mathrm{~nm}$ in size, and no distinct relation between crystallite size and bulk Ir content (9-50 mol\% Ir) is found. An exception is the PdIr-5/C(L) catalyst with the smallest Ir content ( $5 \mathrm{~mol} \%)$ as the crystallites are of slightly higher size, ca. $5 \mathrm{~nm}$.

\section{SEM/TEM studies}

The morphology of monometallic $2 \mathrm{wt} \% \mathrm{Pd} / \mathrm{C}, 2 \mathrm{wt}$ $\% \mathrm{Ir} / \mathrm{C}$ and bimetallic PdIr/C of $\mathrm{L}$ and $\mathrm{H}$ series catalysts is observed in the SEM images in Fig. 3 and Fig. S1. The mono- and bimetallic particles exhibit a spherical-like shape and are well dispersed throughout the carbon support. The individual particles dominate with occasionally seen small aggregates composed of a few particles. As shown in the size histograms, the monometallic $\mathrm{Pd} / \mathrm{C}$ and $\mathrm{Ir} / \mathrm{C}$ 
Figure 3 SEM images of the $2 \mathrm{wt} \% \mathrm{Pd} / \mathrm{C}$ and $2 \mathrm{wt} \% \mathrm{Ir} / \mathrm{C}$ catalysts and the corresponding particle size histograms.
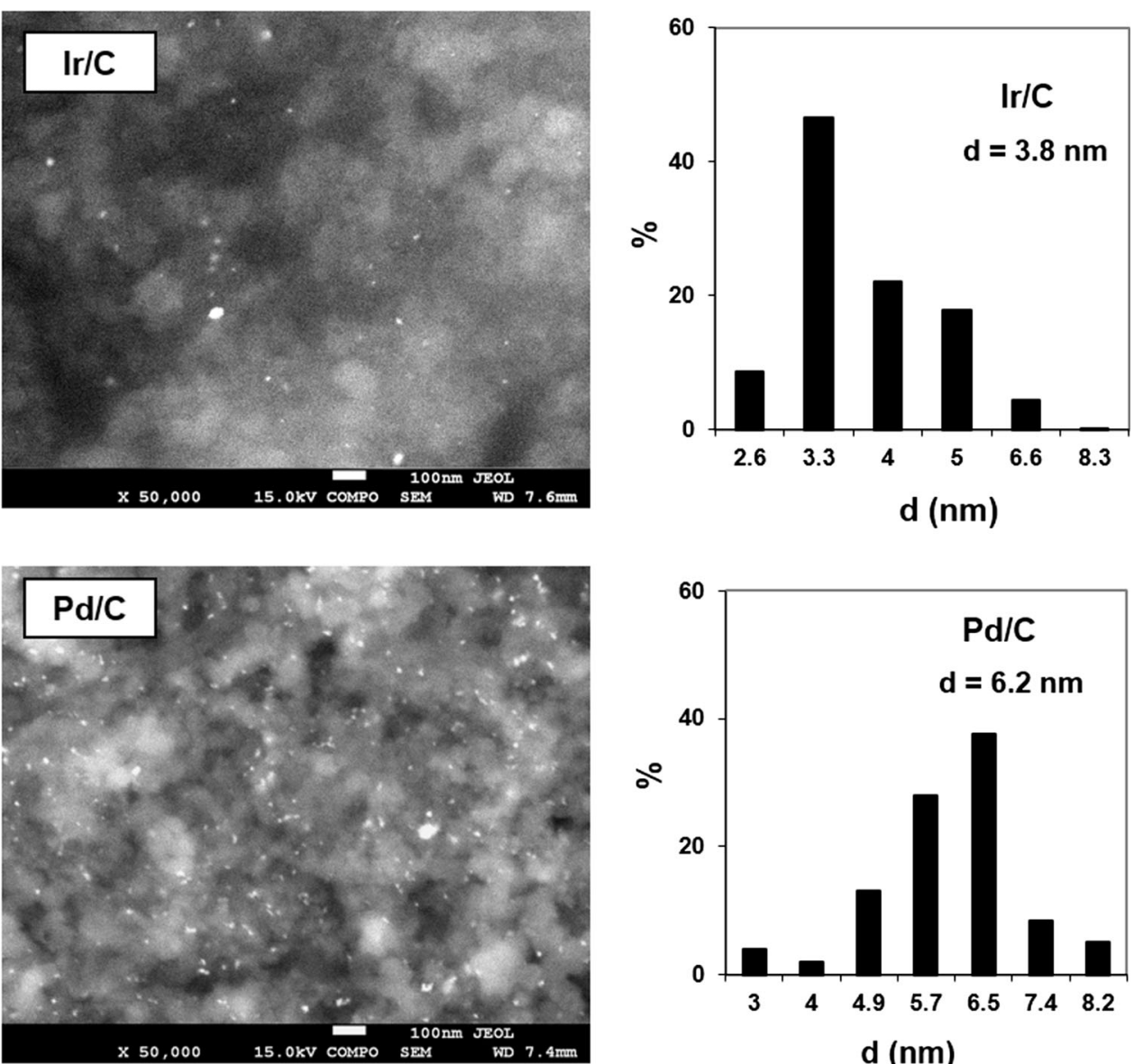

catalysts exhibit a relatively sharp particles size distribution (Fig. 3) with domination (ca. 40\%) of the 6.5nm-sized Pd particles and significantly smaller 3.3$\mathrm{nm}$-sized (50\%) Ir particles. The EDS analyses show the presence of $\mathrm{Pd}$ and $\mathrm{Ir}$ in all the bimetallic particles. The Pd/Ir atomic ratios evaluated from the EDS data (Table 1) are in good agreement with the molar ratio of metal precursors employed.

The TEM and HRTEM images of selected bimetallic catalysts together with the particles distribution diagrams are displayed in Figs. 4 and 5 for L and $\mathrm{H}$ series catalysts, respectively. The particle size distribution profiles show that the bimetallic PdIr particles are in the narrow size range and the average particle sizes did not significantly change for both series of PdIr/C catalysts. The average sizes of the particles calculated from the microscopic images agree reasonably with the results estimated by XRD.

The morphology and the composition of bimetallic PdIr particles, chosen randomly, were studied by the STEM. Energy-dispersive X-ray analysis (EDX) was conducted on several different individual metal particles for each catalyst. The local EDX analyses reveal the bimetallic nature of the nanoparticles as the coexistence of both $\mathrm{Pd}$ and $\mathrm{Ir}$ elements was detected. The obtained average compositions are roughly close to the molar ratio of metal precursors employed in the synthesis.

The nearly monodisperse $\mathrm{Pd}$ and $\mathrm{Ir}$ particles of average size 6 and $3.8 \mathrm{~nm}$, respectively, e.g., similar to those in the present $\mathrm{Pd} / \mathrm{C}$ and $\mathrm{Ir} / \mathrm{C}$ catalysts, were also observed in our previous work dealing with the processes occurring during the preparation of mono (M) and Pd-based bimetallic PdM particles $(\mathrm{M}=\mathrm{Pt}$, $\mathrm{Ru}, \mathrm{Ir}, \mathrm{Au}$ ) by the same $\mathrm{w} / \mathrm{o}$ procedure as that used in the present work [16]. These studies revealed that the nucleation was decisive for the particles formation under these $\mathrm{w} / \mathrm{o}$ conditions evidenced by the proportional growth of the particles size from Ir through Pt and $\mathrm{Rh}$ to Pd. For the bimetallic Pd-based systems, the average particle size was below that of monometallic counterparts [16]. Similar effect, e.g., uniformly dispersed bimetallic particles of the size smaller comparing to the corresponding 
Figure 4 TEM and HRTEM images of selected bimetallic $\mathrm{PdIr} / \mathrm{C}$ catalysts of $\mathrm{L}$ series and the corresponding particle size histograms.
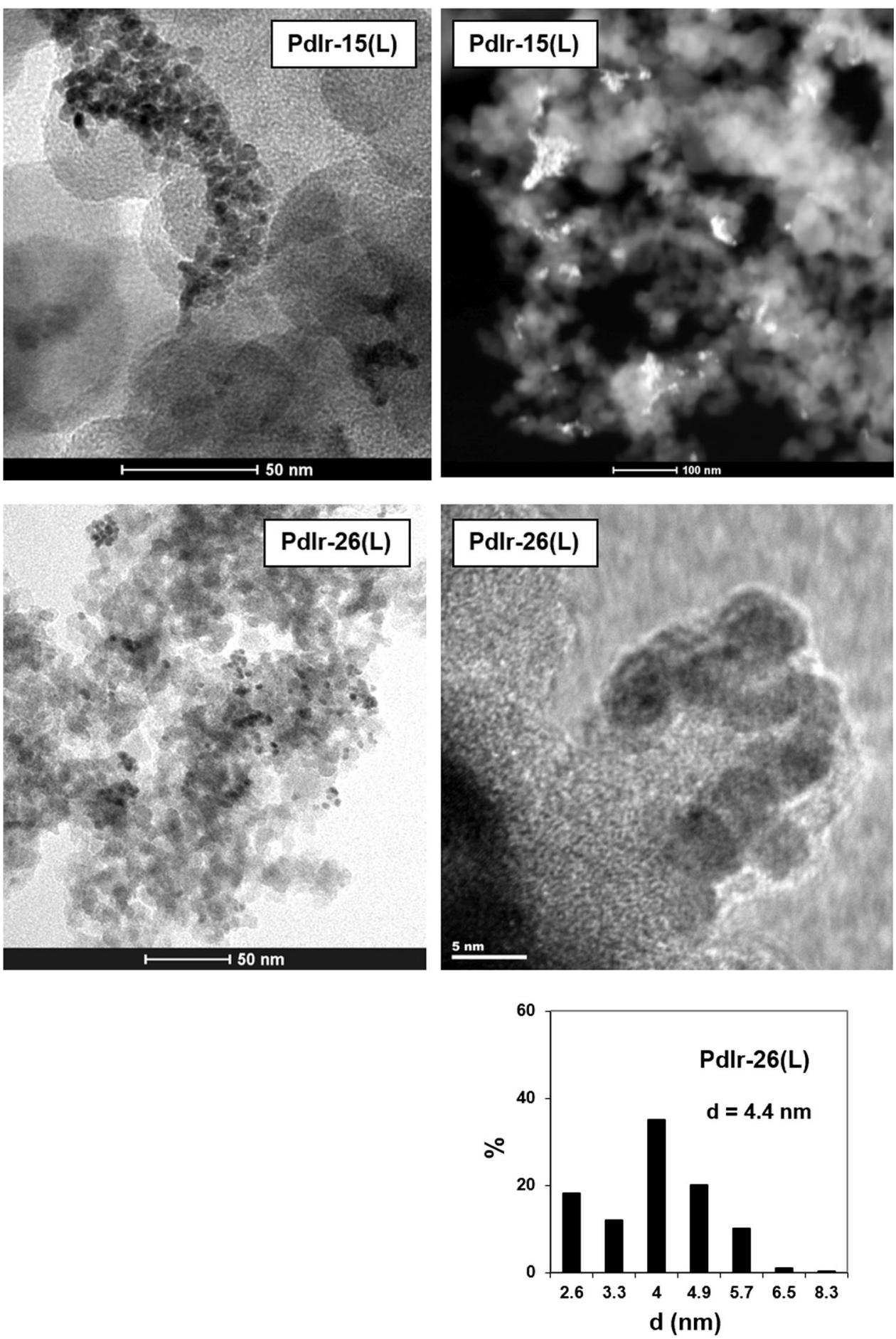

monometallic ones, observed for AuAg [11] PdAu [12], PtAu [13], PtPd [14] particles has also been attributed to a decisive influence of the nucleation processes on the particles formation by a microemulsion procedure.

\section{XPS studies}

The XPS spectra of catalysts displayed the signals characteristic of $\mathrm{C} 1 s, \mathrm{O} 1 s, \mathrm{Pd} 3 d$ and Ir $4 f$ components, whereas no chlorine residuals from the precursors were observed thus indicating complete reduction of the metal ions during the preparation. 
Figure 5 TEM and HRTEM images of selected bimetallic $\mathrm{PdIr} / \mathrm{C}$ catalysts of $\mathrm{H}$ series and the corresponding particle size histograms.
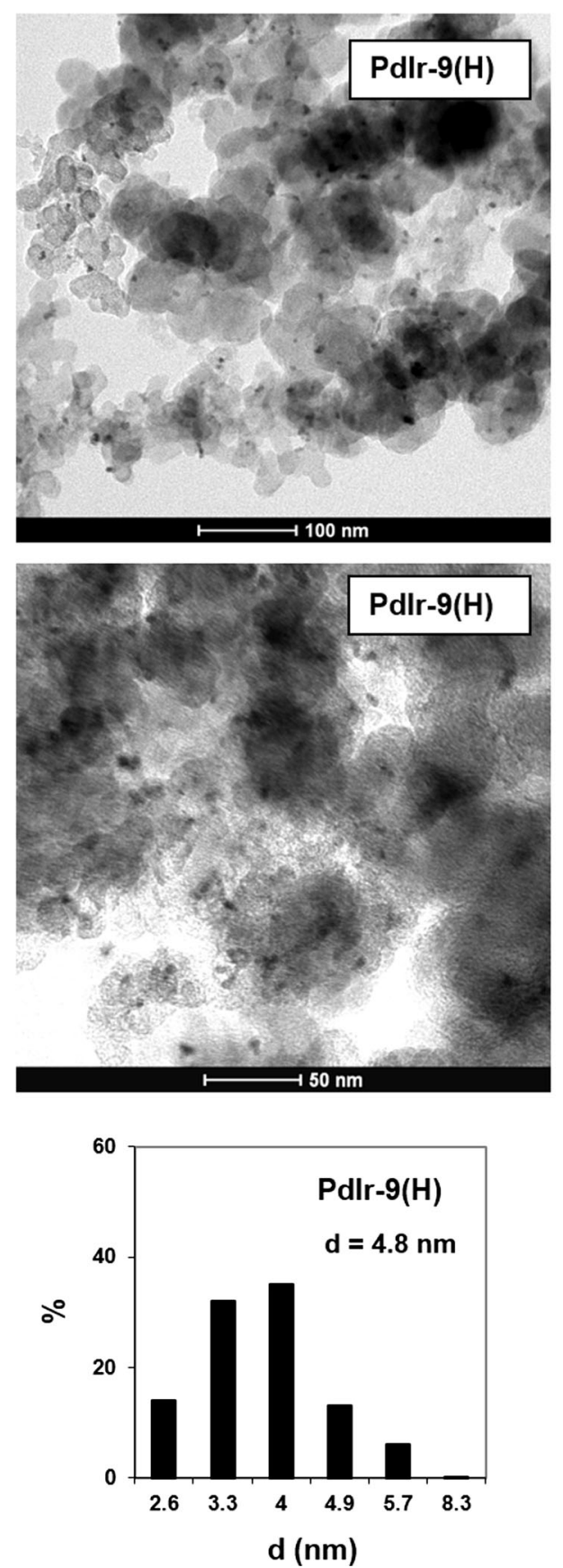
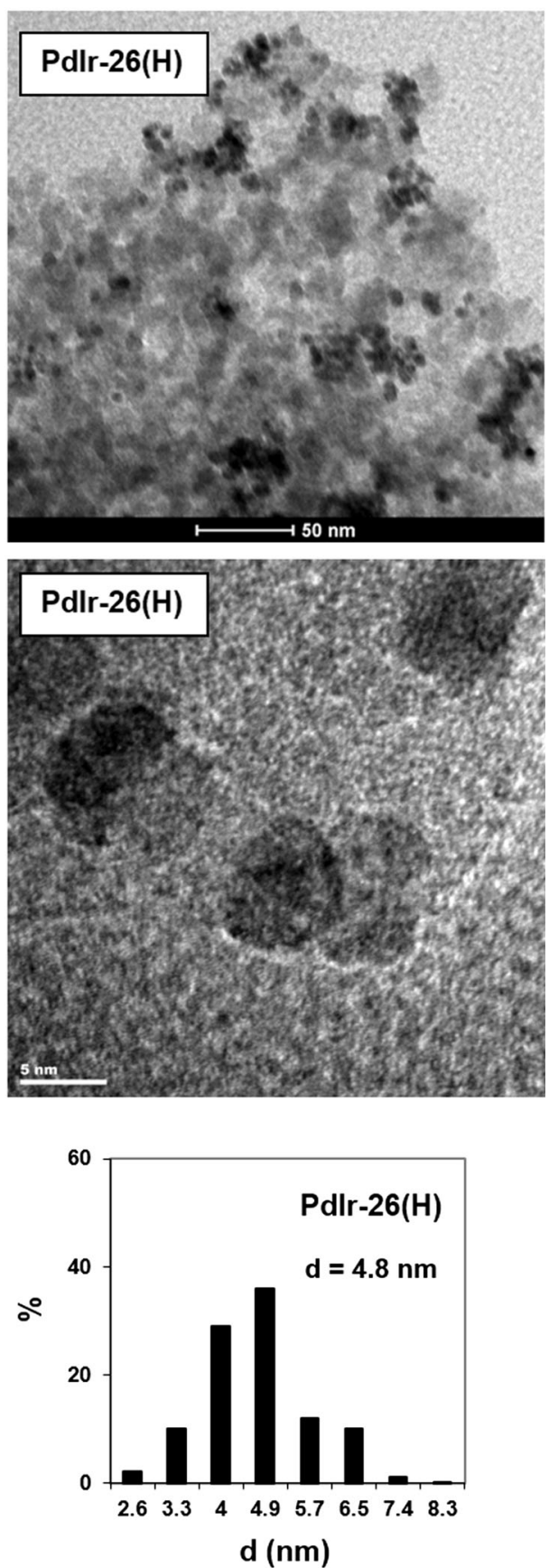

The depth of X-ray penetration is typically in the range of a few nanometers $(6-10 \mathrm{~nm})$. However, the $\mathrm{Pd} / \mathrm{Ir}$ atomic ratios obtained from the XPS data provided a rough insight into the surface composition of the bimetallic particles (Table 2). Comparing the XPS-derived $\mathrm{Pd} / \mathrm{Ir}$ atomic ratios with corresponding bulk Pd/Ir values, a tendency to form a Pddominated surface can be seen in most of the $\mathrm{L}$ series particles (PdIr-9, PdIr-15, PdIr-26, PdIr-35) prepared in diluted precursor solution. On the other hand, the
XPS-calculated $\mathrm{Pd} / \mathrm{Ir}$ atomic ratios are below (PdIr26) or comparable (PdIr-9, PdIr-50) to the corresponding bulk values for the $\mathrm{H}$ series particles synthesized in concentrated precursor solution. This difference indicates that the concentration of precursor solution strongly influenced the particles formation process. The segregation of palladium to the outer shells of the PdIr particles was facilitated in diluted precursor solution (0.02 M, L series). 
Table 2 Surface properties of studied catalysts characterized by $\mathrm{CV}$ and XPS techniques

\begin{tabular}{|c|c|c|c|c|c|c|c|c|}
\hline \multirow[t]{2}{*}{ Catalyst } & & \multicolumn{2}{|c|}{ Surface fraction (from CV) } & \multicolumn{3}{|c|}{$\mathrm{Pd} / \mathrm{Ir}$ atomic ratio } & \multicolumn{2}{|c|}{$\mathrm{BE}(\mathrm{eV}) /$ peak share } \\
\hline & & $\mathrm{Pd}$ & Ir & Bulk & XPS & $\mathrm{CV}$ & $\operatorname{Pd} 3 d_{5 / 2}$ & $\operatorname{Ir} 4 f_{7 / 2}$ \\
\hline $\mathrm{Pd}$ & $\mathrm{H}$ & 1.00 & & & & & $\begin{array}{l}335.6 / 0.60 \\
336.5 / 0.40\end{array}$ & \\
\hline PdIr-5 & $\mathrm{L}$ & 0.87 & 0.13 & 19 & & 6.7 & $335.6 / 0.74$ & $61.0 / 0.92$ \\
\hline $\mathrm{Pd}_{95} \mathrm{Ir}_{5}$ & $\mathrm{H}$ & 0.91 & 0.09 & & 6.33 & 10.1 & $\begin{array}{l}336.6 / 0.26 \\
335.4 / 0.60 \\
336.2 / 0.40\end{array}$ & $\begin{array}{l}62.0 / 0.08 \\
60.7 / 0.73 \\
61.9 / 0.27\end{array}$ \\
\hline $\begin{array}{l}\text { PdIr-9 } \\
\text { Pd }_{91} \mathrm{Ir}_{9}\end{array}$ & $\mathrm{~L}$ & 0.87 & 0.13 & 10 & 14.2 & 6.7 & $\begin{array}{l}335.5 / 0.75 \\
336.9 / 0.25\end{array}$ & $\begin{array}{l}60.8 / 0.51 \\
61.9 / 0.49\end{array}$ \\
\hline & $\mathrm{H}$ & 0.91 & 0.08 & & 9.25 & 11.4 & $\begin{array}{l}335.3 / 0.75 \\
336.7 / 0.25\end{array}$ & $\begin{array}{l}60.8 / 0.62 \\
62.2 / 0.38\end{array}$ \\
\hline $\begin{array}{l}\text { PdIr-15 } \\
\operatorname{Pd}_{85} \operatorname{Ir}_{15}\end{array}$ & $\mathrm{~L}$ & 0.89 & 0.11 & 5.7 & 6.25 & 8.1 & $\begin{array}{l}335.4 / 0.59 \\
336.0 / 0.41\end{array}$ & 61.4 \\
\hline $\begin{array}{l}\text { PdIr-26 } \\
\operatorname{Pd}_{74} \operatorname{Ir}_{26}\end{array}$ & $\mathrm{~L}$ & 0.85 & 0.15 & 2.9 & 6.3 & 5.7 & $\begin{array}{l}335.4 / 0.71 \\
336.2 / 0.29\end{array}$ & $\begin{array}{l}61.2 / 0.66 \\
62.0 / 0.34\end{array}$ \\
\hline & $\mathrm{H}$ & 0.77 & 0.23 & & 0.96 & 3.3 & 335.8 & $\begin{array}{l}61.3 / 0.57 \\
62.5 / 0.43\end{array}$ \\
\hline PdIr-35 & $\mathrm{L}$ & 0.84 & 0.16 & 1.9 & 2.5 & 5.3 & $335.4 / 0.69$ & $61.0 / 0.49$ \\
\hline $\mathrm{Pd}_{65} \mathrm{Ir}_{35}$ & & & & & & & $336.2 / 0.31$ & $62.3 / 0.51$ \\
\hline PdIr-50 & $\mathrm{L}$ & 0.82 & 0.18 & 1 & 0.70 & 4.5 & $335.4 / 0.60$ & $61.0 / 0.64$ \\
\hline $\mathrm{Pd}_{50} \mathrm{Ir}_{50}$ & $\mathrm{H}$ & 0.82 & 0.18 & 1 & 0.86 & 4.5 & $\begin{array}{l}336.2 / 0.40 \\
335.9 / 0.57 \\
336.4 / 0.43\end{array}$ & $\begin{array}{l}62.2 / 0.36 \\
61.5 / 0.32 \\
62.7 / 0.68\end{array}$ \\
\hline $\mathrm{Ir} / \mathrm{C}$ & & & 1.00 & & & & & 62.8 \\
\hline
\end{tabular}

The Pd $3 d$ spectrum of $\mathrm{Pd} / \mathrm{C}$ catalyst shows two palladium states with the proportion given in Table 2. The $\mathrm{Pd} 3 d_{5 / 2}$ binding energy of $335.6 \mathrm{eV}$ with a contribution of $60 \%$ is related to $\mathrm{Pd}$ metal, while the higher energy peak at $336.5 \mathrm{eV}(40 \%)$ could be assigned to oxidized species like the $\mathrm{Pd}-\mathrm{O}$ formed due to surface oxidation of the particles. The peak at ca. $336.5-336.8 \mathrm{eV}$ has been reported for $\mathrm{Pd} 3 d_{5 / 2}$ level of PdO [44, 45].

Systematic studies reported by Holade et al. [44] showed that the type of reducing agent applied for reducing carbon (Vulcan XC-72)-supported Pd catalyst played a crucial role in chemical properties of the formed Pd particles, in particular surface stability under air. The reduction with $\mathrm{NaBH}_{4}$ produced the $\mathrm{Pd}$ metal with some contribution of the $\mathrm{PdO}$ species observed by XPS as the Pd $3 d_{5 / 2}$ peaks at energy of 335.3 and $336.8 \mathrm{eV}$ with surface contents of 53 and 47 at $\%$, respectively. On the other hand, no reflections arising from the crystalline $\mathrm{PdO}$ were observed. According to the authors, reducing agent such as $\mathrm{NaBH}_{4}$ (or hydrazine $\mathrm{N}_{2} \mathrm{H}_{4}$ ) released hydrogen gas in aqueous medium which is absorbed in the Pd lattice to form $\mathrm{PdH}_{x}$ hydride. This could weaken the metallic Pd-Pd bond, hence affecting the electronic properties of the material resulting in easy oxidation to form oxides, most likely PdO. It has been previously reported that palladium oxidation at temperature below $160{ }^{\circ} \mathrm{C}$ was a surface process resulting in partial covering of the metal surface with two-dimensional PdO structures accompanied by a fraction of metastable supersaturated $O_{\mathrm{ads}}$ layer. The bulk $\mathrm{PdO}$ phase was formed in oxidation at high temperature above $350{ }^{\circ} \mathrm{C}$ [45]. The position of the X-ray diffraction line characteristic for crystalline $\mathrm{PdO}$ is marked in XRD patterns (Fig. 1).

Two palladium states can be also observed in most of the PdIr/C catalysts. The contribution of oxidized $\mathrm{Pd}$ species in the PdIr-5/C(H) catalyst is similar to that in pure $\mathrm{Pd} / \mathrm{C}$, whereas it is lower in most of other catalysts with higher Ir content. This effect suggests that the presence of Ir increases Pd stability towards surface oxidation.

The $\mathrm{Pd} 3 d_{5 / 2}$ binding energy of metallic palladium in the PdIr/C catalysts exhibits a small negative shift relative to the binding energy of pure $\mathrm{Pd} / \mathrm{C}$. The 
energy shift is small by ca. $0.1 \mathrm{eV}$ at low bulk Ir content (PdIr-5), but it grows up to ca. $0.2 \mathrm{eV}$ at higher bulk Ir content. However, a positively shifted (by $0.3 \mathrm{eV}$ ) Pd $3 d$ binding energy can be also seen at high bulk Ir content in the particles synthesized at high concentration of the metals precursors, i.e., PdIr26(H) and PdIr-50(H).

The Ir $4 f_{7 / 2}$ binding energy of $60.8 \mathrm{eV}$ was reported for metallic Ir in the iridium foil [46]. The Ir $4 f_{7 / 2}$ binding energy within a range of $61.4-62.6 \mathrm{eV}$ was registered for the oxidized $\mathrm{IrO}_{x}$ depending on the morphology and the hydration degree [46-48]. The $4 f_{7 / 2}$ binding energy of $61.7-61.9 \mathrm{eV}$ was observed for rutile-type crystalline $\mathrm{IrO}_{2}$, whereas the binding energy was higher $62.3-62.5 \mathrm{eV}$ in amorphous oxide structures, presenting short-range ordered IrOx species related to the $\mathrm{Ir}^{3+}$ sites in conjunction with the surface of Ir-OH hydroxide species [47, 48].

The $\operatorname{Ir} 4 f_{7 / 2}$ binding energy of metallic iridium $\operatorname{Ir}^{\circ}$ in the monometallic Ir catalysts was reported in the range of $60.4-61.5 \mathrm{eV}$. For instance, the single Ir $4 f_{7 / 2}$ energy of metallic $\mathrm{Ir}^{\circ}$ was registered at $60.3 \mathrm{eV}$ in the $\mathrm{Ir} / \mathrm{SiO}_{2}$ [49] and at energy of $60.3-60.7 \mathrm{eV}$ in the $\mathrm{Ir} /$ $\mathrm{SiO}_{2}, \mathrm{Ir} / \mathrm{ZrO}, \mathrm{Ir} / \mathrm{TiO}_{2}$ catalysts [50]. On the other hand, two iridium states corresponding to metallic $\mathrm{Ir}^{\circ}$ at $60.9 \mathrm{eV}$ and oxidized $\mathrm{Ir}^{\mathrm{s}+}$ species at $62.1 \mathrm{eV}$ were registered in the $\mathrm{Ir} / \mathrm{TiO}_{2}[51]$ and $\mathrm{Ir} / \gamma-\mathrm{Al}_{2} \mathrm{O}_{3}[52,53]$. These states were observed at 61.1 and $62.8 \mathrm{eV}$ in series of $\mathrm{Ir} / \mathrm{SiO}_{2}$ [54]. In the $5 \% \mathrm{Ir} / \mathrm{C}$ catalyst, Date et al. [55] observed three components of the Ir $4 f_{7 / 2}$ peak ascribed to the metallic $\operatorname{Ir}^{\circ}(60.9 \mathrm{eV})$ and oxidized species $\mathrm{IrO}_{2}(61.5 \mathrm{eV})$ as well as $\mathrm{IrO}_{3}(62.21 \mathrm{eV})$. It is well known that handling Ir catalysts in contact with air even at room temperature resulted in partial oxidation of iridium, especially the iridium nanoparticles [56]. On the other hand, the single Ir $4 f_{7 / 2}$ binding energy of $61.96 \mathrm{eV}$ and $61.54 \mathrm{eV}$ registered for the single-atomic Ir supported on $\mathrm{TiO}_{2}$ and on graphitic carbon nitride, respectively, has been ascribed to the $\mathrm{Ir}^{\mathrm{S}+}$ species of positive charge formed as a result of a charge transfer from Ir atom to the nearest support species [57].

It should be stressed that our bimetallic PdIr and monometallic Ir catalysts were stored in contact with air. The XPS spectrum of our $2 \% \mathrm{Ir} / \mathrm{C}$ catalyst shows a single broad Ir $4 f_{7 / 2}$ peak at binding energy of $62.8 \mathrm{eV}$ which can be ascribed to the oxidized iridium. No reflections of crystalline metallic Ir were observed in the XRD pattern of Ir/C catalyst. Their positions are marked in the XRD patterns presented in Fig. 2.

Two iridium states are registered by XPS in our PdIr/C catalysts, similarly to $\mathrm{PdIr} / \mathrm{TiO}_{2}$ [58], PdIr/ $\mathrm{Al}_{2} \mathrm{O}_{3}$ [52, 53] PdIr/C [30] and PdIr nanoporous aggregates [32]. The lower Ir $4 f_{7 / 2}$ binding energy of $60.8-61.3 \mathrm{eV}$ could be ascribed to the metallic $\mathrm{Ir}^{\circ}$. The second Ir state corresponds to higher Ir $4 f_{7 / 2}$ energy of $62.0-62.7 \mathrm{eV}$ which could be related to amorphous oxidized $\mathrm{IrO}_{x}$. Similarly, as in the case of $\mathrm{Ir} / \mathrm{C}$, no XRD reflections of crystalline $\mathrm{IrO}_{2}$ were registered; the positions characteristic of $\mathrm{IrO}_{2}$ reflections is marked in XRD patterns displayed in Fig. 1. It should be stressed that crystalline rutile-type $\mathrm{IrO}_{2}$ was formed upon oxidation at temperature above $350{ }^{\circ} \mathrm{C}$ [47]. In most of our PdIr/C catalysts, the proportion of the peak arising from the oxidized Ir-species vs. that of Ir metal is within $30-40 \%$, although the oxidized Ir-species predominates over the $\operatorname{Ir}^{\circ}(68 / 32)$ at surface of PdIr-50/C(H) catalyst with equimolar bulk $\mathrm{Pd}$ and Ir contents (Table 2).

In carbon-supported $\mathrm{Pd}_{7} \mathrm{Ir}$ and $\mathrm{Pd}_{5} \mathrm{Ir}$ catalysts prepared using $\mathrm{NaBH}_{4}$, Shen et al. [30] registered similar XPS spectra. Palladium observed in metal $(335.8 \mathrm{eV})$ and oxidized $\mathrm{PdO}_{\mathrm{ads}}$ states $(336.1 \mathrm{eV})$ with proportion of $60 / 40$ was accompanied by the $\operatorname{Ir}^{\circ}$ $(61.2 \mathrm{eV})$ and oxidized $\mathrm{IrO}_{2}(63.48 \mathrm{eV})$ at similar proportion of $75 / 25$, regardless of the Ir bulk content. No diffractions of crystalline PdO and crystalline $\mathrm{IrO}_{2}$ were observed for these catalysts (Fig. 1).

The Pd $3 d$ binding energy in various PdIr systems was reported to be positively or negatively shifted relative to the $\mathrm{Pd}$. The positive shift observed in thin films of Pd-Ir metal [28], alumina-supported $\mathrm{Pd}_{45} \mathrm{Ir}_{55}$ nanoclusters [24] and $\mathrm{PdIr} / \mathrm{Al}_{2} \mathrm{O}_{3}$ catalysts $[49,50]$ has been related to the higher electron affinity of $\mathrm{Ir}$ $\left(112 \mathrm{~kJ} \mathrm{~mol}^{-1}\right)$ compared to that of Pd $\left(54 \mathrm{~kJ} \mathrm{~mol}^{-1}\right)$ resulting in electron-donating features of $\mathrm{Pd}$ and electron-accepting ability of Ir. The negatively shifted $\mathrm{Pd} 3 d$ binding energy was registered for $\mathrm{PdIr} / \mathrm{SiO}_{2}$ [41] and PdIr/C electrocatalysts [31]. This Pd-Ir electronic effect has been explained taking into account a difference in Pd and Ir work functions being in close contact. The work function of $\mathrm{Pd}$ is $5.2 \mathrm{eV}\left[5.6 \mathrm{eV}\right.$ for $\left.\mathrm{Pd}\left(\begin{array}{lll}1 & 1 & 1\end{array}\right)\right]$, and the $\mathrm{Ir}$ is $5.1 \mathrm{eV}$; therefore, the charge is transported from Ir to Pd [31]

The change in binding energy of metal core level reflects the shift of its d-band center relative to Fermi level. Negative shift of the binding energy corresponds to a downshift of d-band center [59, 60]. 
Computational studies [61-63] have predicted that a $\mathrm{Pd}$ overlayer or Pd alloyed into the first layer of $\operatorname{Ir}(11$ 1) will show a decreased d-band center energy by ca. $0.4-0.73 \mathrm{eV}$, relative to pure $\mathrm{Pd}$, which resulted in the experimentally determined weaker adsorption strength of small molecules like $\mathrm{CO}, \mathrm{H}_{2}$ [64]. A significant downshift of the d-band center was also found by the DFT studies for the modelled nanocluster of the $\operatorname{Ir}$ (core)-Pd(shell) configuration, whereas a small d-band upshift was found for the same Pd-Ir cluster but of Janus-Pd configuration [26].

In view of these literature reports, a modification of $\mathrm{Pd}$ electron properties could be postulated in our bimetallic PdIr/C catalysts.

\section{CV characterization}

The CV curves of the catalysts registered in Ar-saturated $0.5 \mathrm{M}$ sulfuric acid solution $(50 \mathrm{mV} / \mathrm{s})$ are collected in Fig. 6. In all studied catalysts, monometallic $\mathrm{Pd} / \mathrm{C}$ and bimetallic PdIr/C samples, the Pd content is equal to $2 \mathrm{wt} \%$, while the content of Ir increases. The current density normalized to the Pd mass on the electrode $\left(\mathrm{mA} \mathrm{mg} \mathrm{Pd}{ }^{-1}\right)$ is taken into discussion. Two pairs of well-resolved hydrogen absorption/desorption peaks can be seen on all catalysts. The inset in Fig. 6 presents the magnified view of the hydrogen desorption (oxidation) potential regions. The first peak at more negative potential (0.1-0.2 V vs. RHE) originates mainly from the oxidation of hydrogen from the $\beta-\mathrm{PdH}_{x}$ hydride phase, whereas the smaller one at more positive potential (ca. $0.28 \mathrm{~V}$ vs. RHE) corresponds to the oxidation of surface adsorbed hydrogen.

No current due to hydrogen absorption/desorption was measured on our $2 \mathrm{wt} \% \mathrm{Ir} / \mathrm{C}$ catalyst in consistence with previous reports [33, 34, 36]. The overall shape of hydrogen desorption peaks on the PdIr/C catalysts differs from that on Pd/C (Fig. 6). In general, the PdIr/C samples generate less intense hydrogen desorption peaks located at more negative potential compared to $\mathrm{Pd} / \mathrm{C}$.

Electrochemical measurements for thin films of Pdbased bimetallic samples such as Pd-Au, Pd-Rh, Pd$\mathrm{Ru}$ and $\mathrm{Pd}-\mathrm{Cu}[65,66]$ and for carbon-supported $\mathrm{Pd}-$ Pt particles [67] showed reduced intensity of hydrogen absorption/desorption peaks accompanied by a negative shift of the peak potential relative to pure $\mathrm{Pd}$. These effects attributed to the presence of Pdalloyed structures were dependent on the metal type
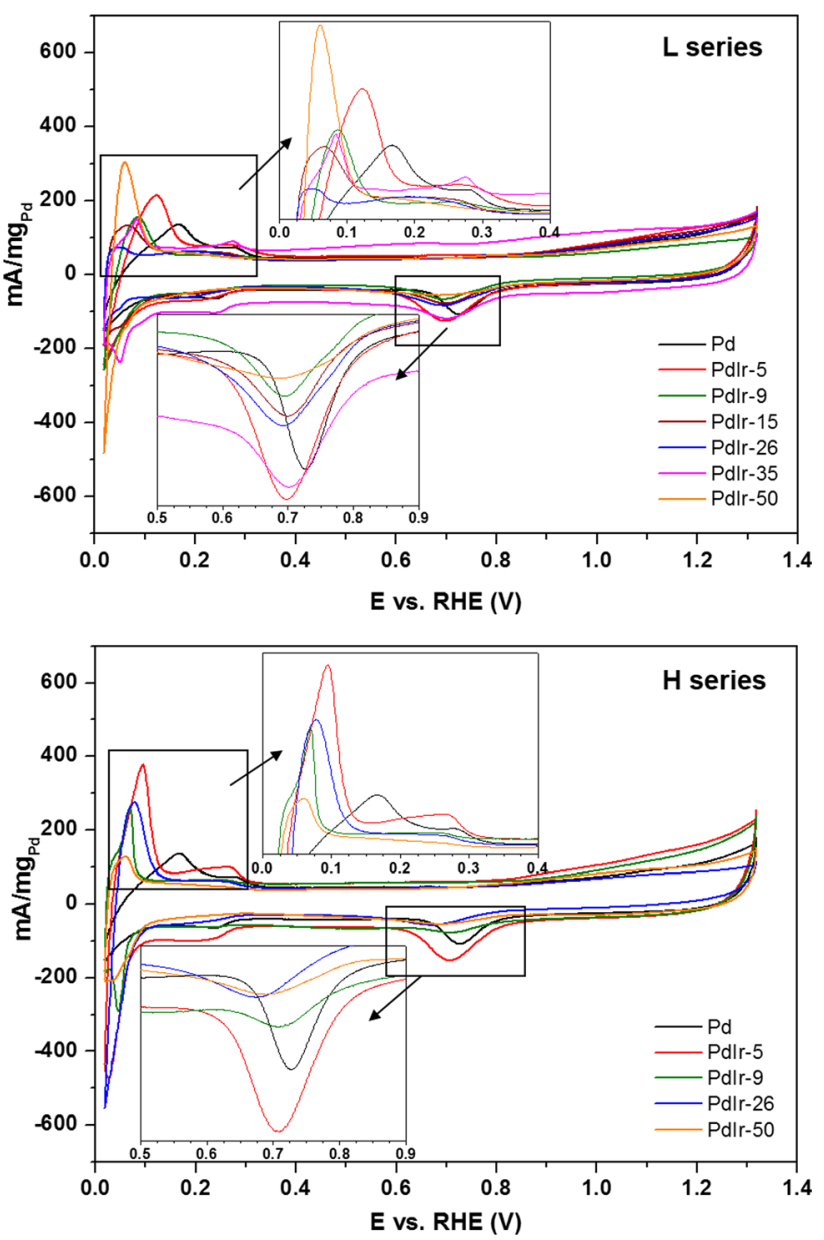

Figure 6 Cyclic voltammograms registered for $2 \mathrm{wt} \% \mathrm{Pd} / \mathrm{C}$ and bimetallic PdIr/C catalysts of $\mathrm{L}$ and $\mathrm{H}$ series in $\mathrm{N}_{2}$-saturated $0.5 \mathrm{M}$ sulfuric acid solution, scan rate of $50 \mathrm{mV} \mathrm{s}^{-1}$. The insets present magnified view of hydrogen desorption region $(0.0-0.4 \mathrm{~V})$ and metal surface reduction region $(0.5-0.9 \mathrm{~V})$.

(Rh, Pt, Au, Ag) [66]. More negative potential indicating the facilitated desorption of hydrogen has been ascribed to weaker hydrogen bonding due to the modification of the Pd electronic properties by added metal [65]. Wang et al. [33] also observed that the hydrogen adsorption/desorption peaks gradually decreased with growing Ir content in the Pd-Ir/C samples being the smallest at the $\mathrm{Pd} / \mathrm{Ir}$ atomic ratio of 1 .

As shown in Fig. 6, when compared to monometallic Pd/C catalyst, the PdIr/C catalysts of $\mathrm{L}$ series show less intense hydrogen desorption peaks except two samples with the smallest PdIr-5/C (L) and the highest PdIr-50/C(L) bulk Ir contents. The latter two catalysts display intense hydrogen desorption peaks. On the other hand, relatively intense 
hydrogen desorption peaks can be seen for the $\mathrm{H}$ series catalysts. Their intensity slowly decreases with growing bulk Ir content, and the PdIr-50/C(H) sample with the highest Ir amount generates only small hydrogen desorption peak (Fig. 6). The first hydrogen desorption peak on both $\mathrm{L}$ and $\mathrm{H}$ series of PdIr/C catalysts is observed at more negative potential ( $\mathrm{E}$ (H), Table 1) compared to Pd/C. A negative shift of potential can be seen even at $5 \mathrm{~mol} \% \mathrm{Ir}$, but it becomes more pronounced at $15 \mathrm{~mol} \%$ Ir. However, with further growth of bulk Ir content the potential almost stabilizes at ca. $0.06 \mathrm{~V}$, e.g., the level which is around $100 \mathrm{mV}$ more negative compared to $\mathrm{Pd} / \mathrm{C}$ $(0.167 \mathrm{~V})$. A trend of the potential shift is similar to catalysts of $\mathrm{L}$ and $\mathrm{H}$ series. Thus, hydrogen bonding is weaker in our bimetallic $\mathrm{PdIr} / \mathrm{C}$ catalysts than in the $\mathrm{Pd} / \mathrm{C}$. The recent DFT studies found a significant weakening of the strength of hydrogen bonding in the model system consisting of the Pd atomic layer deposited on the $\operatorname{Ir}\left(\begin{array}{lll}1 & 1 & 1\end{array}\right)$ substrate ascribed to a downshift of the palladium d-band center due to the Ir-species [62]. For the pseudomorphic Pd monolayer on the crystalline Ir substrate, Kibller et al. [64] measured negatively shifted hydrogen desorption peak potential by ca. $170 \mathrm{mV}$ which is well correlated with the calculated by Ruban et al. [61] downshift of the d-band center by $0.4 \mathrm{eV}$. The potential of the second hydrogen oxidation peak (at ca. $0.28 \mathrm{~V}$ ) has been related to the surface composition of the $\mathrm{Pd}$ alloys [68]. A linear relationship was found between the negative shift of the potential and growing surface fraction of $\mathrm{Rh}$ in the Pd-Rh films [68]. As Fig. 6 shows, the second hydrogen desorption peak locates at slightly lower potential on PdIr/C samples than on $\mathrm{Pd} / \mathrm{C}$, thus evidencing that the surface of PdIr particles consists of iridium.

The chemisorption measurements of $\mathrm{H}_{2}$ gas also revealed reduced capacity of hydrogen sorption in the bulk PdIr alloys as compared with pure Pd metal [43]. The solubility of hydrogen in the bulk PdIr alloys stopped above approximately 8 at\% Ir [43]. Zlotea et al. [69] also found ca. 3.5-times lower hydrogen solubility $\left(25^{\circ} \mathrm{C}, 10^{-4}-10^{-1} \mathrm{MPa}\right)$ for the $\mathrm{Pd}_{51} \mathrm{Ir}_{49}$ nanoclusters supported on silica-alumina as compared to pure $\mathrm{Pd}(0.18 \mathrm{H} / \mathrm{M}$ vs. ca. $0.7 \mathrm{H} / \mathrm{Pd})$. No $\mathrm{PdH}_{x}$ hydride formation has been observed by the TPR measurements for the $\mathrm{Pd}-\mathrm{Ir} / \mathrm{Al}_{2} \mathrm{O}_{3}$ catalysts [52]. In general, the extent of $\beta-\mathrm{PdH}$ hydride formation was found to be a semiquantitative but very sensitive approach to evaluate the alloying extent in the bimetallic systems like $\mathrm{Pd}-\mathrm{Ag}, \mathrm{Pd}-\mathrm{Au}, \mathrm{Pd} \mathrm{Re}$, etc. [70]. The Pd-hydride formation is a bulk phenomenon. As a result, the amount of hydrogen sorbed to form the hydride $(\mathrm{H} / \mathrm{Pd}$ ratio) in these bimetallic systems decreases (from ca. 0.7 for pure $\mathrm{Pd}$ ) in proportion to the fraction of alloying metal incorporated [70]. The inhibited hydride formation has been explained by the "valence electron concentration concept" considering the ability of alloying metal to donate electrons to the band system of Pd. Similar electronic effect has been invoked to explain an inhibited hydride formation in the PdIr bulk systems [43].

The suppression of the Pd-hydride formation in our PdIr/C catalysts manifests to various extents depending on the Ir content and the $\mathrm{L}$ or $\mathrm{H}$ preparation method. The comparison of the $\mathrm{CV}$ curves clearly shows that the Pd-hydride formation is to high extent inhibited in the PdIr particles of L series formed at low concentration of the metals precursors. It might be related to the Pd-Ir alloyed structure also observed by the XRD results (Fig. 2). The exceptions are the catalysts with the lowest PdIr-5/C(L) and the highest PdIr-50/C(L) bulk Ir content with less suppressed hydride formation.

On the other hand, much higher hydrogen insertion observed in the $\mathrm{H}$ series particles synthesized at high concentration of the metals precursors (Fig. 6) suggests a lower contribution of the Pd-Ir alloyed phase. It might suggest that partially segregated metals phases are also formed in these PdIr particles like the domains of crystalline palladium enabling the Pd-hydride formation.

The potential zone $(0.5-0.9 \mathrm{~V})$ corresponding to the reduction of surface oxidized species allows for a rough estimation of the metal surface composition expressed by a surface fraction of Ir and Pd (inset in Fig. 6). This method has been successfully applied to determine the surface composition of bimetallic systems in the metal films [71, 72] and supported particles such as $\mathrm{PdAu} / \mathrm{C}, \mathrm{PdPt} / \mathrm{C}$ and $\mathrm{PdAuPt} / \mathrm{C}$ [73, 74]. The CV curves of all our Pd-Ir/C catalysts display a single oxide reduction peak at the potential located between those of pure Pd and Ir. A single surface oxide reduction peak indicates homogeneity of alloy surface composition [71, 72]. The CV curves of PdIr/C do not show noticeable peaks due to the reduction of oxidized forms of pure Pd and Ir. Surface fractions of Ir and Pd are calculated accordingly to the previous method [71] assuming that the 
potential of reduction peak of the alloy surface oxides $\left(\mathrm{E}_{\mathrm{P}, \text { ALLOY }}\right)$ depends linearly on the surface composition (Eq. 2).

$E_{\mathrm{P}, \text { Alloy }}=X_{\mathrm{Pd}} E_{\mathrm{P}, \mathrm{Pd}}+X_{\mathrm{Ir}} E_{\mathrm{P}, \mathrm{Ir}}$

where $X_{\mathrm{Pd}}$ and $X_{\mathrm{Ir}}$ are the surface atomic fractions of $\mathrm{Pd}$ and $\mathrm{Ir}$, while $E_{\mathrm{P}, \mathrm{Pd}}, E_{\mathrm{P}, \mathrm{Ir}}$ are the potentials of oxide reduction peak for the pure $\mathrm{Pd}(0.727 \mathrm{~V})$ and $\mathrm{Ir}$ $(0.505 \mathrm{~V})$ in the monometallic catalysts.

Surface fractions of $\mathrm{Ir}$ and $\mathrm{Pd}$ calculated from Eq. (2) are summarized in Table 2. Both Pd and Ir appear within the surface layers of all studied PdIr catalysts, but at various proportions determined mainly by the synthesis procedure, $\mathrm{H}$ or $\mathrm{L}$. The correlation between the bulk content of Ir and its surface fraction is displayed in Fig. 7a. The relationship for the $\mathrm{Pd} / \mathrm{Ir}$ surface ratio being a measure of the particles surface enrichment in Pd is displayed in Fig. $7 \mathrm{~b}$. The dotted lines correspond to the case when the bulk and the surface fractions of Ir are the same. Different relations are seen for the $\mathrm{L}$ and $\mathrm{H}$ series catalysts. For two catalysts of L series, PdIr-5(L) and PdIr-9(L), with low bulk Ir content of $5 \mathrm{~mol} \%$ and $9 \mathrm{~mol} \%$, the surface fraction of Ir distinctly exceeds the bulk Ir content. At higher bulk Ir contents, the surface fractions of Ir are below the corresponding bulk values and only slowly increase with growing bulk Ir content from 0.11 in the PdIr-15/C(L) to 0.18 in PdIr-50/C(L) catalyst. For these catalysts, the calculated surface $\mathrm{Pd} / \mathrm{Ir}$ atomic ratios exceed the corresponding bulk $\mathrm{Pd} / \mathrm{Ir}$ values, consistent with a trend revealed by the XPS-derived surface $\mathrm{Pd} / \mathrm{Ir}$ ratio (Table 2). Thus, both XPS and CV methods show that these PdIr particles with a medium Ir content (15$35 \mathrm{~mol} \%$ ) formed at low concentration of the metals precursors have a Pd-dominated surface with minor
Ir contribution. It might be expected that the $\mathrm{Pd}$ segregation affects mostly a few surface atomic layers of the particles. However, the PdIr particles with the lowest $5 \mathrm{~mol} \%$ Ir content $\left(\mathrm{Pd}_{95} \mathrm{Ir}_{5}\right)$ irrespective of the precursor concentration, L or $\mathrm{H}$ procedure, are characterized by the surface enriched in Ir evidenced by the surface Pd/Ir atomic ratios below the corresponding bulk values (Table 2).

Somewhat different effects can be observed in the $\mathrm{H}$ series catalysts prepared at high concentration of the metals precursors (Fig. 7a, b). Except the PdIr-5/C (H) catalyst with the smallest bulk Ir content, the surface Ir fractions in the catalysts with higher Ir content PdIr-9/C(H) and PdIr-26/C(H) are almost close to the corresponding bulk values. Similar relation can be seen from XPS data (Table 2). This suggests almost complete suppression of the palladium segregation in the PdIr particles synthesized in concentrated precursor solution.

At equimolar Ir and Pd bulk contents $\left(\mathrm{Pd}_{50} \mathrm{Ir}_{50}\right)$, there is no essential difference between the surface compositions of the $\mathrm{L}$ and $\mathrm{H}$ particles as they have surface fraction of Ir below the bulk value, thus indicating the Pd-rich surface. In conclusion, the concentration of the metals precursors has significant effect on the bimetallic particles formation processes.

At a moderate Ir content (15-35 $\mathrm{mol} \%)$, the diluted precursor solution $(0.02 \mathrm{M}, \mathrm{L}$ series) promotes alloyed Pd-Ir systems with the particles surface enriched in Pd. As a result, the overall composition of the PdIr particles prepared in diluted precursor solution (L series) was a gradient in Pd content from the outer to the inner region, except the smallest bulk Ir content ( $5 \mathrm{~mol} \%)$. This observation is supported by the strongly reduced capacity of sorbed hydrogen as well as by the XRD patterns (Fig. 2).
Figure 7 Surface fraction of Ir (a) and surface $\mathrm{Pd} / \mathrm{Ir}$ atomic ratio (b) as a function of the bulk Ir content in the PdIr/C catalysts of $\mathrm{L}$ and $\mathrm{H}$ series.
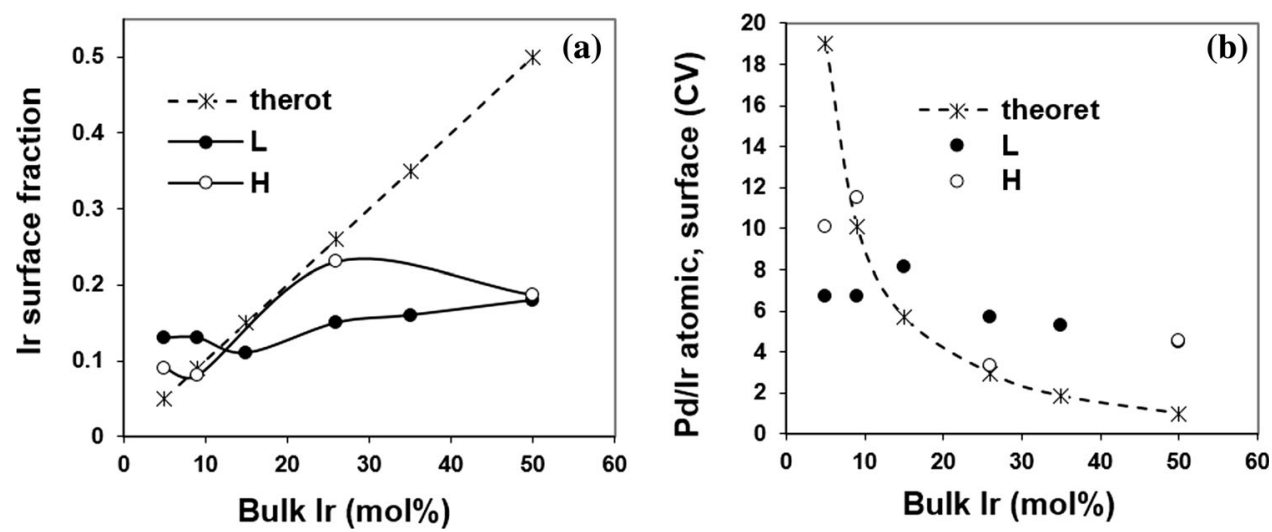
In the PdIr nanoparticles prepared at high concentrations of the metals precursors $(0.2 \mathrm{M}, \mathrm{H}$ series), the surface segregation of $\mathrm{Pd}$ is definitively much weaker. The XPS and CV measurements reveal almost equal surface and bulk $\mathrm{Pd} / \mathrm{Ir}$ atomic ratios at moderate bulk Ir contents, 9 and $26 \mathrm{~mol} \%$. Simultaneously, relatively high intensity of hydrogen-arising peaks (Fig. 6) is detected by $\mathrm{CV}$ in these particles. Thus, some contribution of the segregated phases such as the domains of crystalline palladium like in the "ball-cup"-type configurations could be expected.

The results obtained for our PdIr particles with a moderate Ir content well support the molecular dynamic simulation for the bimetallic systems ( $\mathrm{Au}-$ $\mathrm{Pt}, \mathrm{Rh}-\mathrm{Pt}, \mathrm{Pd}-\mathrm{Ir}$ ) showing that the tendency of the core-shell structures formation decreased in the particles formed at high concentration of the metals precursors [8-10]. However, at very low bulk Ir content $(5 \mathrm{~mol} \%)$ the particles with the Ir segregated to the surface were formed irrespective of the concentration of the metals precursors. These particles exhibit relatively high hydrogen sorption (Fig. 6). This implies that when the amount of palladium ions strongly exceeded that of iridium ions in the micelle (precursor solution), the nucleation and clustering processes of palladium predominated. Maybe, because of too low amount of Ir ions in the micelle the iridium nucleation process was hindered at the beginning of the particles formation process. As a result, the particles with the core consisting mostly of $\mathrm{Pd}$ and surface shells enriched in Ir are formed. A small shift of the Pd binding energy in the spectra of these catalysts might suggest the presence of Ir clusters/islands in the vicinity of palladium.

At equal Pd and Ir bulk contents, the $\mathrm{Pd}_{50} \mathrm{Ir}_{50}$ nanoparticles with Pd-enriched surface are formed, but they essentially differ in the bulk arrangement of the $\mathrm{Pd} / \mathrm{Ir}$ components. High capacity of sorbed hydrogen registered for the PdIr-50(L) particles suggests the structure composed of phase-separated $\mathrm{Pd} /$ Ir domains. On the other hand, the $\mathrm{Pd}-\mathrm{Ir}$ alloyed structure is formed in the $\mathrm{PdIr}-50 / \mathrm{C}(\mathrm{H})$ prepared at high concentration. The simulation results indicated that as long as the co-nucleation generating heterogeneous nuclei is faster compared to homogeneous nucleations, mixing is favored from the beginning, giving rise to a nanoalloy structure $[9,10]$. Thus, it might be speculated that heterogeneous co-nucleation dominated over the homogenous processes in our system at high concentration of the metals precursors (0.2 M, H series).

In agreement with previous conclusions concerning formation and nanostructures of other bulk-immiscible metals, such as Au-Rh and Ag-Rh [1, 4], the importance of the kinetics in governing the structure of bimetallic PdIr nanoparticles formed under our microemulsion procedure might be postulated. Besides, the structural phenomena driven by the thermodynamics (phase segregation) have also an impact.

\section{Formic acid electrooxidation}

The cyclic voltammograms of formic acid (FA) oxidation over studied catalysts are reported in Fig. 8. No current due to FA oxidation was measured on the $2 \mathrm{wt} \% \mathrm{Ir} / \mathrm{C}$ catalyst indicating that pure Ir is inactive, which is consistent with previous data [33, 34]. The maximum current for the FA oxidation on $2 \% \mathrm{Pd} / \mathrm{C}$ is observed at the potential of $0.54 \mathrm{~V}$ (RHE) which corresponds to the FA oxidation via the direct pathway $[33,34]$.

A distinct influence of the Ir content and the preparation procedure, $\mathrm{L}$ or $\mathrm{H}$, on the electroactivity of studied PdIr/C can be seen in Fig. 8 comparing the Pd-mass activity $\left(\mathrm{mA} \mathrm{mgPd}^{-1}\right)$. Note that all catalysts have the same Pd content of $2 \mathrm{wt} \%$, whereas the $\mathrm{Ir}$ content increases. As a result, the Pd mass on the electrode was the same in all electroactivity tests $\left(10 \mu \mathrm{g} \mathrm{Pd} \mathrm{cm}^{2}\right)$, whereas the content of Ir rose. The current density of FA oxidation expressed as mA/ $\mathrm{cm}^{2}$ is reported in Fig. S2. The Pd-mass activity ( $\mathrm{mA}$ $\mathrm{mgPd}^{-1}$ ) of all the $\mathrm{H}$ series catalysts is lower as compared to that of pure Pd (Fig. 8). On the other hand, the $\mathrm{L}$ series catalysts exhibit mass activity higher than that of pure $\mathrm{Pd} / \mathrm{C}$, except the one with equimolar Pd and Ir contents PdIr-50/C(L). The most active is the PdIr-15/C(L) catalyst with the mass activity which surpasses more than three times that of $\mathrm{Pd} / \mathrm{C}$.

As mainly the surface of the metal particles participates in the FA oxidation, the activities expressed by the TOF values seem more appropriate to discuss the role of Ir in the Pd activity. Metal dispersions (D, $\%)$ in the studied catalysts are similar, within the range of $25-28 \%$ (Table 1). The values of turnover frequency (TOF) for the FA electrooxidation calculated according to Eq. (3) [75-77] are collected in Table 1. 

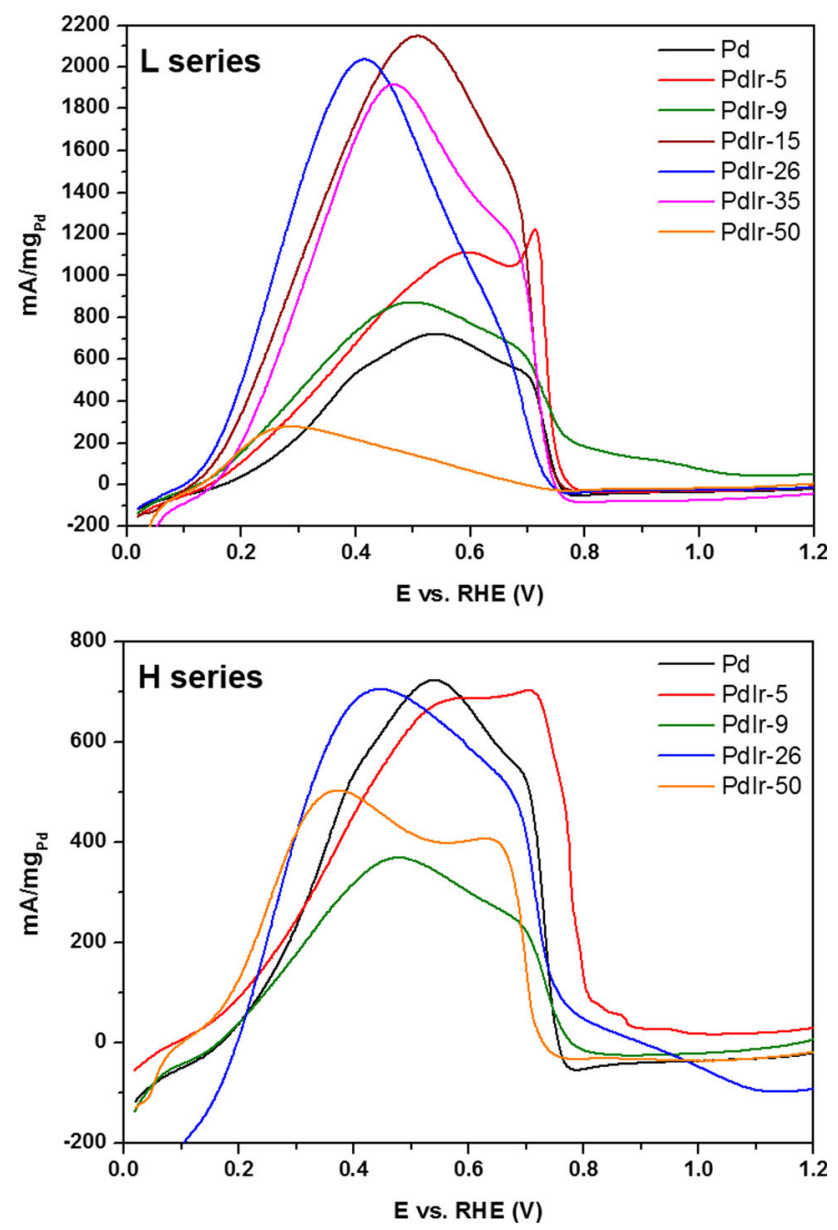

Figure 8 Cyclic voltammetry of $2 \mathrm{wt} \% \mathrm{Pd} / \mathrm{C}$ and bimetallic PdIr/ $\mathrm{C}$ catalysts of $\mathrm{L}$ and $\mathrm{H}$ series in $0.5 \mathrm{M}$ sulfuric acid with $0.5 \mathrm{M}$ formic acid at a scan rate of $50 \mathrm{mV} \mathrm{s}^{-1}$ normalized by mass of $\mathrm{Pd}$ $\left(\mathrm{mA} \mathrm{mg} \mathrm{Pd}{ }^{-1}\right)$.

$\mathrm{TOF}=i_{k} /$ ne $N_{\mathrm{s}}$

where $i_{k}$ is the specific current density at potential of $0.54 \mathrm{~V}, n$ is the number of electrons transferred, $e$ is elementary charge, and $n_{\mathrm{s}}$ is atomic surface density.

The values of TOF are calculated at the potential of $0.54 \mathrm{~V}$ (vs. RHE) corresponding to the maximum current for pure $\mathrm{Pd} / \mathrm{C}$ catalyst [29]. It is generally accepted that formic acid oxidizes solely through the dehydrogenation path over Pd surface [29], and therefore, $n=2$ is assumed in the calculation.

In both $\mathrm{L}$ and $\mathrm{H}$ series, the active sites in the catalysts with the lowest ( $5 \mathrm{~mol} \%$ Ir) and the highest (50 mol\% Ir) bulk Ir contents are less active as compared to that of pure Pd (Table 1). The active sites in $\mathrm{H}$ series catalysts with moderate Ir contents, namely PdIr-9/C(H) and PdIr-26/C(H), exhibit activity comparable to that of $\mathrm{Pd} / \mathrm{C}$ what is evidenced by the
TOF values of 11.03 and $12.71 \mathrm{~s}^{-1}$ similar to that of the $\mathrm{Pd} / \mathrm{C}\left(11.36 \mathrm{~s}^{-1}\right)$. In contrast, the active sites in the $\mathrm{L}$ series catalysts display the TOF values exceeding that of Pd/C (Table 1). The active sites in the PdIr-15/C (L) catalyst are especially active as its $\mathrm{TOF}=29.1 \mathrm{~s}^{-1}$ is 3-times higher as compared to pure Pd/C $\left(11.36 \mathrm{~s}^{-1}\right)$. Thus, a promotion of Pd activity toward FA electrooxidation is attained over the $\mathrm{L}$ series catalysts with moderate bulk Ir content (from 15 to $35 \mathrm{~mol} \%$ ). The observed activity promotion could be ascribed to the Pd-Ir synergy.

The FA electrooxidation can proceed via two alternative reaction pathways dependent on the nature of metal sites. The direct pathway leading to carbon dioxide is given by Eq. 4

$\mathrm{HCOOH} \rightarrow \mathrm{CO}_{2}+2 \mathrm{H}^{+}+2 \mathrm{e}^{-}$

In the undesirable dehydration pathway (Eq. 5), formic acid is firstly oxidized to carbon monoxide intermediate which is a poison for $\mathrm{Pd}[33,34]$. Then, $\mathrm{CO}$ is oxidized to $\mathrm{CO}_{2}$.

$\mathrm{HCOOH} \rightarrow \mathrm{CO}+\mathrm{H}_{2} \mathrm{O}$

The direct pathway predominates on Pd surface, but some contribution of "CO-pathway" also existed and slow deactivation of Pd catalysts was commonly observed, related to poisoning by adsorption of $\mathrm{CO}$. An enhanced electroactivity of Ir-containing Pd catalysts was related to the modification of Pd electronic structure by Ir accompanied by the decreased $\mathrm{CO}$ adsorption strength [33, 78].

The potential of FA oxidation peak over the PdIr/C catalysts is negatively shifted relative to that of $\mathrm{Pd} / \mathrm{C}$ and the potential shift increases as the bulk Ir content grows (Table 1). This tendency can be seen for both series catalysts. A negative shift of the FA oxidation peak potential indicating easier oxidation of FA has been commonly related to an electronic effect. The FA electrooxidation current revealed a volcano shape relationship against the energy of the d-band center in the Pd and Pd-based alloys [65, 79]. As the d-band center in the bimetallic systems shifts away from the Fermi level, the adsorption strength of the formate intermediate $\mathrm{HCOO}_{\mathrm{ad}}$ on the active sites weakened. At the optimum energy of d-band center, the activity reached a maximum value [79]. Beyond this optimal value, the activity decreased as the bond strength between the adsorbed $\mathrm{HCOO}$ and Pd becomes too weak. For series of $\mathrm{PdPt} / \mathrm{C}$ catalysts with various $\mathrm{Pt}$ contents, Zhang et al. [67] reported that the highest 
current of FA oxidation obtained on the $\mathrm{Pd}_{0.9} \mathrm{Pt}_{0.1} / \mathrm{C}$ catalyst was accompanied by a moderate shift of the FA oxidation potential. More negative shift of the FA oxidation potential observed at higher Pt content was accompanied by a decreased FA oxidation current.

When the maximum current densities of FA electrooxidation $\left(\mathrm{mA} / \mathrm{cm}^{2}\right)$ on the $\mathrm{PdIr} / \mathrm{C}$ catalysts are plotted against the FA oxidation peak potential ( $E$, $V$ ), a volcano-type variation is observed (Fig. 9). The highest current corresponds to a mildly negative shift of the FA oxidation potential. The highest activity attained over L series catalysts, PdIr-15, PdIr-26, and PdIr-35, with moderate Ir contents (15-35\%) corresponds to a moderate shift of the FA oxidation potential. The obtained current densities (and TOF) are 2.6, 2.0 and 1.5-times higher than that of pure Pd. In these catalysts, the surface $\mathrm{Pd} / \mathrm{Ir}$ ratio ranges from 8 to 5.3 (Table 2) which might be speculated to be a rough approximation of the Ir coordination number of 6 as in the $\mathrm{Pd}_{6} \mathrm{Ir}$ cluster. This type of cluster could be formed taking into account that the atomic radius of Pd atom and Ir atom does not strongly differ. These surface clusters seem to be the most probable in the PdIr-15 catalyst with the smallest Ir surface fraction. At somewhat higher Ir surface fraction in the PdIr-26 and PdIr-35 particles, the Pd-Ir ensembles with contiguous two or more Ir-Ir atoms might be also expected. Their presence might strengthen the adsorption of formate $\left(\mathrm{COO}_{\mathrm{ad}}\right)$ intermediate as $\mathrm{Ir}$ is known to facilitate the adsorption of $\mathrm{C}-\mathrm{O}$ bond in the molecules such as furfural or crotonaldehyde [80, 81].

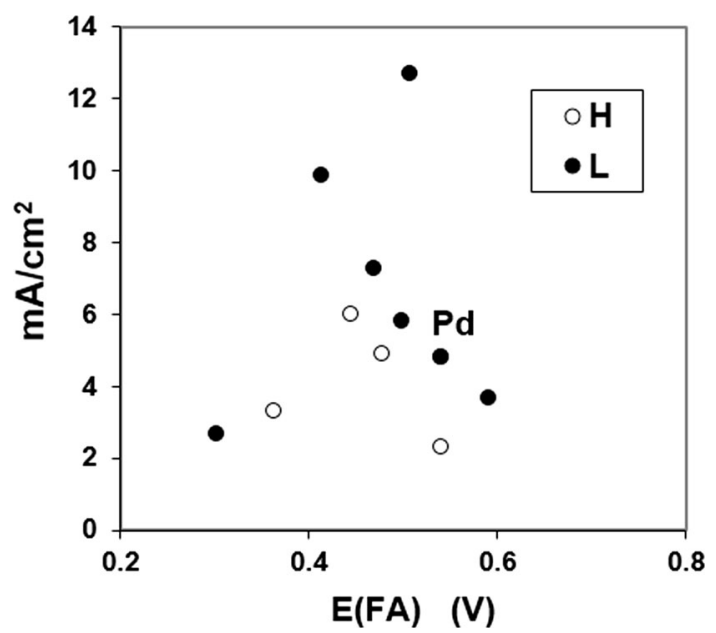

Figure 9 The maximum current density of formic acid (FA) electrooxidation $\left(\mathrm{mA} \mathrm{cm}^{-2}\right.$ ) for the PdIr/C catalysts of $\mathrm{L}$ and $\mathrm{H}$ series against the potential of maximum FA oxidation peak (E, V).
In these catalysts, the Pd electronic properties were modified what is evidenced by the more negative hydrogen desorption peak potential compared to pure $\mathrm{Pd} / \mathrm{C}$ and negatively shifted $\mathrm{Pd} 3 d$ binding energy relative to pure $\mathrm{Pd} / \mathrm{C}$ (Table 2).

Thus, the obtained relation between the Ir content and electroactivity of our PdIr/C series L catalysts showing that the $\mathrm{Pd}_{85} \operatorname{Ir}_{15}$ composition corresponds to the most active catalyst (Table 1) is consistent with the recent results reported by Bao et al. [78] who found that the catalyst with optimum $\mathrm{Pd} / \mathrm{Ir}$ ratio is needed to achieve the best FA electrooxidation performance. Among series of multiwalled carbon nanotubes-supported catalysts with various $\mathrm{Pd} / \mathrm{Ir}$ proportions, the $\mathrm{Pd}_{79} \mathrm{Ir}_{21}$ displayed the highest FA electroactivity. The enhancement of activity has been suggested by the authors to be the result of an appropriate $\mathrm{Pd} / \mathrm{Ir}$ surface composition as the $\mathrm{CO}_{\text {ads }}$ formation requires at least three adjacent precious metal atoms. The appropriate content of Ir is required as introduction of Ir atoms resulted in noncontinuous $\mathrm{Pd}$ sites, thus inhibiting poisoning by $\mathrm{CO}$ and favoring the direct pathway [78]. Our results support this hypothesis and indicate that the surface compositions correspond to the $\mathrm{Pd} / \mathrm{Ir}$ atomic ratio of ca. 6 attained in our catalysts at the bulk composition of Pd85Ir15 and Pd74Ir26 (Table 1).

The lower electroactivity of $\mathrm{H}$ series catalysts could result from the increasing surface fraction of Ir and/ or somewhat lower Ir dispersion because of the presence of iridium islands clusters on the particles surface. This would result in the reduced amounts of available Pd active sites and weaker electron modification of the Pd sites due to lower contribution of the Pd-Ir interface species. The presence of these surface island-type species is accompanied by the relatively high capacity of sorbed hydrogen attributed to partially separate metal domains in the PdIr particles of series $\mathrm{H}$. This indicates that a well-known high clustering tendency of the Pd and Ir which is the result of restricted Pd and Ir metal miscibility manifested distinctly at high concentration of the Pd and Ir precursors solutions.

The maximum FA oxidation current $(2148,2037$ and $1905 \mathrm{~mA} \mathrm{mgPd}^{-1}$ ) on the most active L series catalysts, i.e., PdIr-15, PdIr-26 and PdIr-35, respectively, corresponds to 2.9-2.6-fold increase when compared with $\mathrm{Pd} / \mathrm{C}\left(728 \mathrm{~mA} \mathrm{mgPd}^{-1}\right)$ at $30-70 \mathrm{mV}$ more negative oxidation potential (Fig. 8). It can be seen that these Pd-mass activities obtained in our 
PdIr/C catalysts are of similar range as the values reported by Chen et al. [34] who observed the highest Pd-mass activity (1954 mA/mgPd) at the Ir content of $10-16 \mathrm{~mol} \%(\mathrm{Pd} / \mathrm{Ir}$ mass ratio of $3 / 1-5 / 1)$ in the PdIr/C catalysts at $80-85 \mathrm{mV}$ more negative FA peak potential. This activity was improved by 1.6 -factor when compared with the Pd (1189 $\left.\mathrm{mA} \mathrm{mgPd}{ }^{-1}\right)$. However, higher Pd-mass activity equal to $3756 \mathrm{~mA}$ $\mathrm{mgPd}^{-1}$ at $150 \mathrm{mV}$ more negative potential has been attained over Ir/C@Pd catalyst consisting of the Pdlike islands decorating the $\mathrm{Ir} / \mathrm{C}$ surface $(\mathrm{Pd} / \mathrm{Ir}$ atomic ratio of $7 / 3$ ) [36]. Thus, it seems that further modification of our catalyst is required. Preparation of the PdIr particles of average size smaller than the $4 \mathrm{~nm}$ in the catalysts studied in the present work seems to be a promising way to further improve the activity for FA electrooxidation reaction.

The applied microemulsion strategy proves to be an effective approach to control the nanostructure of bimetallic Pd-Ir nanoparticles which is the key factor determining the PdIr/C catalytic activity for the formic acid electrooxidation reaction. By altering the $\mathrm{Pd} / \mathrm{Ir}$ proportion and the concentration of metals precursors, a range of the PdIr structures from an alloying at atomic scale up to the segregated ones with randomly distributed single-phase domains were synthesized. The FA catalytic synergies were provided by the alloyed Pd-Ir nanoparticles of appropriate surface compositions.

\section{Conclusions}

Two series of PdIr/C catalysts were prepared by the "water-in-oil" microemulsion method with different bulk Ir contents using low (0.02 M, L series) and high $(0.2 \mathrm{M}, \mathrm{H}$ series) concentrations of the metals precursors. The characterization results showed that the $\mathrm{w} / \mathrm{o}$ procedure provided the mono- and bimetallic particles of controlled and uniform size which resulted in homogeneous microstructural and surface properties. The controlled and homogeneous surface properties of the synthesized metal particles enabled the identification of the experimental factors promoting the formation of alloyed PdIr structures. The bimetallic PdIr particles have average size of ca. $4 \mathrm{~nm}$, which is comparable to that of $\operatorname{Ir}(3.8 \mathrm{~nm})$ but much smaller than the size of Pd $(6.2 \mathrm{~nm})$. The synthesis conditions including the concentration of the metals precursors largely determined the microstructure of the PdIr particles with a moderate Ir content (15-35 mol\%) including structural (phase separation/alloying, the $\mathrm{Pd}$ segregation to surface) and the surface properties (surface composition and the arrangement of constituents). At the lowest Ir bulk content, $5 \mathrm{~mol} \%$, regardless of the preparation method the $\mathrm{Pd}_{95} \mathrm{Ir}_{5}$ particles consist of the dominating crystalline $\mathrm{Pd}$ core and Ir-rich surface. In the bimetallic PdIr particles synthesized at high concentration of the metals precursors (H series), a high $\mathrm{Pd}-$ Ir clustering tendency manifested distinctly. As a result, the particles of $\mathrm{H}$ series with partially phase segregated structures are characterized by Pd-crystalline domains. In these particles, the bulk and surface $\mathrm{Pd} / \mathrm{Ir}$ atomic ratios are almost close. In contrast, largely Pd-Ir alloyed structures with the Pd-rich surface were formed at low concentration of the metals precursors $(0.02 \mathrm{M})$. With growing bulk Ir content in the L series particles (from 15 to $50 \mathrm{~mol} \%$ ), the surface fraction of Ir slowly increased from 0.11 to 0.18 .

The catalytic efficiency of PdIr bimetallic systems for the FA electrooxidation reaction depended largely on the preparation conditions. The synergistic properties leading to the enhanced electroactivity manifested only over the alloyed structures of PdIr, while it is not achieved for the phase-segregated PdIr systems. This implies that electroactivity of $\mathrm{H}$ series catalysts did not exceeded that of pure Pd. On the other hand, the L series catalysts displayed much higher electroactivity than pure Pd. The L series $\mathrm{PdIr} / \mathrm{C}$ catalysts of the most attractive properties are the ones with the Pd/Ir surface ratio of ca. 6 achieved at a moderate bulk Ir content of $15-35 \mathrm{~mol} \%$. They exhibit high 2.6-2.9-fold increase of the Pd-mass activity when compared with $\mathrm{Pd} / \mathrm{C}$ at $30-70 \mathrm{mV}$ more negative oxidation potential.

\section{Acknowledgements}

This research was funded by the statutory research found of ICSC PAS (Jerzy Haber Institute of Catalysis and Surface Chemistry, Polish Academy of Sciences). T. Szumełda acknowledges financial support received under the action Funds for Young Researchers organized by the Director of Jerzy Haber Institute of Catalysis and Surface Chemistry, Polish Academy of Sciences.

\section{Springer}




\section{Compliance with ethical standards}

Conflict of interest All authors declare that they have no conflict of interest.

Open Access This article is licensed under a Creative Commons Attribution 4.0 International License, which permits use, sharing, adaptation, distribution and reproduction in any medium or format, as long as you give appropriate credit to the original author (s) and the source, provide a link to the Creative Commons licence, and indicate if changes were made. The images or other third party material in this article are included in the article's Creative Commons licence, unless indicated otherwise in a credit line to the material. If material is not included in the article's Creative Commons licence and your intended use is not permitted by statutory regulation or exceeds the permitted use, you will need to obtain permission directly from the copyright holder. To view a copy of this licence, visit http://creativecommons.org/licen ses/by $/ 4.0 /$.

Electronic supplementary material: The online version of this article (https://doi.org/10.1007/ s10853-020-05277-z) contains supplementary material, which is available to authorized users.

\section{References}

[1] Konuspayeva Z, Afanasiev P, Nguyen TS, Di Felice L, Morfin F, Nguyen NT, Nelayah J, Ricolleau C, Li ZY, Yuan J, Berhault G, Piccolo L (2015) Au-Rh and Au-Pd nanocatalysts supported on rutile titania nanorods: structure and chemical stability. Phys Chem Chem Phys 17:2811228120

[2] Piccolo L, Li ZY, Demiroglu L, Moyon F, Konuspayeva Z, Berhault G, Afanasiev P, Lefebvre W, Yuan J, Johnston RL (2016) Understanding and controlling the structure and segregation behaviour of AuRh nanocatalysts. Sci Rep 6:35226-36234

[3] Essinger-Hileman ER, Decicco D, Bondi JF, Schaak RE (2011) Aqueous room-temperature synthesis of $\mathrm{Au}-\mathrm{Rh}, \mathrm{Au}-$ $\mathrm{Pt}, \mathrm{Pt}-\mathrm{Rh}$, and $\mathrm{Pd}-\mathrm{Rh}$ alloy nanoparticles: fully tunable compositions within the miscibility gaps. J Mater Chem 21:11599-11604

[4] Chantry RL, Atanasov I, Siriwatcharapiboon W, Khanal BP, Zubarev ER, Horswell SL, Johnston RL, Li ZY (2013) An atomistic view of the interfacial structures of AuRh and AuPd nanorods. Nanoscale 5:7452-7457

[5] Tojo C, Buceta D, López-Quintela MA (2017) On metal segregation of bimetallic nanocatalysts prepared by a one-pot method in microemulsion. Catalysts 7:68-85

[6] Sanchez-Dominguez M, Boutonnet M (2016) Synthesis of nanostructured catalytic materials from microemulsions. Catalysts 6:4-8

[7] Lopez-Quintela MA (2003) Synthesis of nanomaterials in microemulsions: formation mechanisms and growth control. Curr Opin Colloid Interface Sci 8:137-144

[8] Tojo C, Buceta D, López-Quintela MA (2018) Slowing down kinetics in microemulsions for nanosegregation control: a simulation study. J Phys Chem C 122:20006-20018

[9] Barroso F, Tojo C (2011) Modelling of nano-alloying and structural evolution of bimetallic core-shell nanoparticles obtained via the microemulsion route. J Colloid Interface Sci 363:73-83

[10] Barroso F, Tojo C (2013) Designing bimetallic nanoparticle structures prepared from microemulsions. J Phys Chem C 117:17801-17813

[11] Chen D-H, Chen C-J (2002) Formation and characterization of $\mathrm{Au}-\mathrm{Ag}$ bimetallic nanoparticles in water-in-oil microemulsions. J Mater Chem 12:1557-1562

[12] Wu ML, Chen DH, Huang TC (2001) Synthesis of Au/Pd bimetallic nanoparticles in reverse micelles. Langmuir 17:3877-3883

[13] Wu ML, Chen DH, Huang TC (2001) Preparation of $\mathrm{Au} / \mathrm{Pt}$ bimetallic nanoparticles in water-in-oil microemulsions. Chem Mater 13:599-606

[14] Wu M, Chen D, Huang T (2001) Preparation of $\mathrm{Pd} / \mathrm{Pt}$ bimetallic nanoparticles in water/AOT/isooctane microemulsion. J Colloid Interface Sci 243:102-108

[15] Finney EE, Finke RG (2008) Nanocluster nucleation and growth kinetic and mechanistic studies: a review emphasizing transition-metal nanoclusters. J Colloid Interface Sci 317:351-374

[16] Szumełda T, Drelinkiewicz A, Kosydar R, Góral-Kurbiel M, Gurgul J, Duraczyńska D (2017) Formation of Pd-group VIII bimetallic nanoparticles by the "water-in-oil" microemulsion method. Colloids Surfaces A 529:246-260

[17] Buceta D, Tojo C, Vukmirovic MB, Deepak FL, LópezQuintela MA (2015) Controlling bimetallic nanostructures by the microemulsion method with subnanometer resolution using a prediction model. Langmuir 31:7435-7439

[18] Ahmed J, Ramanujachary KV, Lofland SE, Furiato A, Gupta G, Shivaprasad SM, Ganguli AK (2008) Bimetallic Cu-Ni nanoparticles of varying composition (CuNi3, CuNi, Cu3Ni). Colloids Surfaces A Physicochem Eng Asp 331:206-212 
[19] Toshima N, Yonezawa T (1998) Bimetallic nanoparticlesnovel materials for chemical and physical applications. New J Chem 22:1179-1201

[20] Tojo C, Buceta D, López-Quintela MA (2015) Understanding the metal distribution in core-shell nanoparticles prepared in micellar media. Nanoscale Res Lett 10:339-349

[21] Tripathi SN, Bharadwaj SR, Chandrasekharaiah MS (1991) The Ir-Pd (iridium-palladium) system. J Phase Equilibria 12:603-605

[22] Turchi PEA, Drchal V, Kundnovsky J (2006) Stability and ordering properties of fcc alloys based on $\mathrm{Rh}, \mathrm{Ir}, \mathrm{Pd}$, and Pt. Phys Rev B 74:064202-1-064202-12

[23] Kolb B, Müller S, Botts DB, Hart GLW (2006) Ordering tendencies in the binary alloys of Rh, Pd, Ir, and Pt: density functional calculations. Phys Rev B 74:144206

[24] Morfin F, Nassreddine S, Rousset JL, Piccolo L (2012) Nanoalloying effect in the preferential oxidation of $\mathrm{CO}$ over Ir-Pd catalysts. ACS Catal 2:2161-2168

[25] Piccolo L, Nassreddine S, Aouine M, Ulhaq C, Geantet C (2012) Supported Ir-Pd nanoalloys: size-composition correlation and consequences on tetralin hydroconversion properties. J Catal 292:173-180

[26] Fan TE, Demiroglu I, Hussein HA, Liu TD, Johnston RL (2017) DFT study of the structure, chemical ordering and molecular adsorption of Pd-It nanoalloys. Phys Chem Chem Phys 19:27090-27098

[27] Aas N, Bowker M (1994) The preparation, characterisation and oxygen adsorption on $\operatorname{Ir} / \operatorname{Pd}(110)$ alloys. Surf Sci 310:113-127

[28] Schwarz RB, Harms U, Jain H (2004) Elastic stiffness of interfaces studied by Rayleigh waves. Mater Sci Eng A 375377:194-200

[29] Meng H, Zeng D, Xie F (2015) Recent development of Pdbased electrocatalysts for proton exchange membrane fuel cells. Catalysts 5:1221-1274

[30] Shen SY, Zhao TS, Xu JB (2010) Carbon-supported bimetallic PdIr catalysts for ethanol oxidation in alkaline media. Electrochim Acta 55:9179-9184

[31] Neto AO, da Silva SG, Buzzo GS, de Souza RFB, Assumpção MHMT, Spinacé EV, Silva JCM (2015) Ethanol electrooxidation on PdIr/C electrocatalysts in alkaline media: electrochemical and fuel cell studies. Ionics 21:487-495

[32] Xu X, Wang X, Huo S, Chen Z, Zhao H, Xu J (2018) Facile synthesis of PdIr nanoporous aggregates as highly active electrocatalyst towards methanol and ethylene glycol oxidation. Catal Today 318:157-166

[33] Wang X, Tang Y, Gao Y, Lu T (2008) Carbon-supported PdIr catalyst as anodic catalyst in direct formic acid fuel cell. J Power Sources 175:784-788
[34] Chen J, Wang G, Wang X, Tian J, Zhu S, Wang R (2013) Enhanced formic aid electro-oxidation on PdIr nanoparticles prepared by ethylene glycol-assisted $\mathrm{NaBH}_{4}$ reduction process. J Nanosci Nanotechnol 13:7008-7011

[35] Adams BD, Asmussen RM, Ostrom CK, Chen A (2014) Synthesis and comparative study of nanoporous palladiumbased bimetallic catalysts for formic acid oxidation. J Phys Chem C 118:29903-29910

[36] Chen J, Li Y, Gao Z, Wang G, Tian J, Jiang C, Zhu S, Wang $\mathrm{R}$ (2013) Ultrahigh activity of $\mathrm{Pd}$ decorated $\mathrm{Ir} / \mathrm{C}$ catalyst for formic acid electro-oxidation. Electrochem commun 37:2427

[37] Szumełda T, Drelinkiewicz A, Kosydar R, Gurgul J (2014) Hydrogenation of cinnamaldehyde in the presence of $\mathrm{PdAu} /$ C catalysts prepared by the reverse "water-in-oil" microemulsion method. Appl Catal A Gen 487:1-15

[38] Szumelda T, Drelinkiewicz A, Mauriello F, Dziedzicka A, Duraczynska D, Gurgul J (2019) Controlling the bimetallic structure of supported $\mathrm{Pd} / \mathrm{Ir}$ catalysts via the "water-in-oil" microemulsion method. J Chem. https://doi.org/10.1155/ 2019/4314975

[39] Szumełda T, Drelinkiewicz A, Lalik E, Kosydar R, Duraczyńska D, Gurgul J (2018) Carbon-supported $\mathrm{Pd}_{100-x} \mathrm{Au}_{x}$ alloy nanoparticles for the electrocatalytic oxidation of formic acid: influence of metal particles composition on activity enhancement. Appl Catal B Environ 221:393-405

[40] Holade H, Morais C, Servat K, Napporn TW, Kokoh KB (2016) Enhancing the available specific surface area of carbon supports to boost the electroactivity of nanostructured $\mathrm{Pt}$ catalysts. Phys Chem Chem Phys 16:25609-25620

[41] Yang H, Huang C, Yang F, Yang X, Du L, Liao S (2015) Mesoporous silica nanoparticle supported PdIr bimetal catalyst for selective hydrogenation, and the significant promotional effect of Ir. Appl Surf Sci 357:558-563

[42] Hong R, He Y, Miao C, Feng J, Li D (2017) Fabrication of supported Pd-Ir mesocrystal catalyst for hydrogenation of 2-ethylanthraquinone. Catal Lett 147:1802-1810

[43] LaPrade M, Allard KD, Lynch JF (1974) Flanagan TB absorption of hydrogen by iridium/palladium substitutional. J Chem Soc Far Trans 1(70):1615-1630

[44] Holade Y, Canaff C, Poulin S, Napporn TW, Servar K, Kokoh KB (2016) High impact of the reducing agent on palladium nanomaterials: new insights from X-ray photoelectron spectroscopy and oxygen reduction reaction. RSC Adv 6:12627-12637

[45] Zemlyanov D, Aszalos-Kiss B, Kleimenov E, Teschner D, Zafeiratos S, Havecker M, Knop-Gericke A, Schlögl R, Gabasch H, Unterberger W, Hayek K, Klötzer B (2006) In situ XPS study of Pd(111) oxidation. Part 1: 2D oxide formation in $10^{-3}$ mbar $\mathrm{O}_{2}$. Surf Sci 600:983-994 
[46] Freakley SJ, Ruiz-Esquius J, Morgan DJ (2017) The X-ray photoelectron spectra of $\mathrm{Ir}, \mathrm{IrO}_{2}$ and $\mathrm{IrCl}_{3}$ revisited. Surf Interface Anal 49:794-799

[47] Pfeifer V, Jones TE, Velez JJV, Massue C, Arrigo R, Teschner D, Girsdies F, Scherzer M, Greiner MT, Allan J, Hashagen M, Weinberg G, Piccinin S, Hävecker M, KnopGericke A, Schögl R (2016) The electronic structure of iridium and its oxides. Surf Interface Anal 48:261-273

[48] Abbott DF, Lebedev D, Waltar K, Povia M, Nachtegaal M, Fabbri E, Copéret C, Schmidt TJ (2016) Iridium oxide for the oxygen evolution reaction: correlation between particle size, morphology, and the surface hydroxo layer from operando XAS. Chem Mater 28:6591-6604

[49] Marzialetti T, Oportus M, Ruiz D, Fierro JLG, Reyes P (2018) Enantioselective hydrogenation of 1-phenyl-1,2propanedione, ethyl pyruvate and acetophenone on $\mathrm{Ir} / \mathrm{SiO}_{2}$ catalysts: effect of iridium loading. Catal Today 133135:711-719

[50] Reyes P, Aguirre MC, Pecchi G, Fierro JLG (2000) Crotonaldehyde hydrogenation on Ir supported catalysts. J Mol Catal A Chem 164:245-251

[51] Reyes P, Salinas D, Campos C, Oportus M, Murcia J, Rojas H, Borda G, García Fierro JL (2010) Selective hydrogenation of furfural on $\mathrm{Ir} / \mathrm{TiO}_{2}$ catalysts. Quim Nova 33:777-780

[52] Hong R, He Y, Feng J, Li D (2017) Fabrication of supported $\mathrm{Pd}-\mathrm{Ir} / \mathrm{Al}_{2} \mathrm{O}_{3}$ bimetallic catalysts for 2-ethylanthraquinone hydrogenation. AICHE J 63:3955-3965

[53] Ziaei-azad H, Yin CX, Shen J, Hu Y, Karpuzov D, Semagina N (2013) Size- and structure-controlled mono- and bimetallic Ir-Pd nanoparticles in selective ring opening of Indian. J Catal 300(2013):113-124

[54] Chimentão RJ, Oliva H, Belmar J, Morales K, Mäki-Arvela P, Wärnå J, Murzin DY, Fierro JLG, Llorca J, Ruiz D (2019) Selective hydrodeoxygenation of biomass derived 5-hydroxymethylfurfural over silica supported iridium catalysts. Appl Catal B Environ 241:270-283

[55] Date NS, Henge AM, Huang KW, Chikate RC, Rode CV (2018) Single pot selective hydrogenation of furfural to 2-methylfuran over carbon supported iridium catalysts. Green Chem 20:2027-2031

[56] Kuznetsova LI, Kuznetsova NI, Koscheev SV, Zaikovskii VI, Lisitsyn AS, Kaprielova KM, Kirillova NV, Twardowski Z (2012) Carbon-supported iridium catalyst for reduction of chlorate ions with hydrogen in concentrated solutions of sodium chloride. Appl Catal A Gen 427-428:8-15

[57] Tian S, Gong W, Chen W, Lin N, Zhu Y, Feng Q, Xu Q, Fu Q, Chen C, Luo J, Yan W, Zhao H, Wang D, Li Y (2019) Regulating the catalytic performance of single-atomic-site Ir catalyst for biomass conversion by metal-support interactions. ACS Catal 2019:5223-5230
[58] Li J, Wu G, Guan N, Li L (2012) NO selective reduction by hydrogen over bimetallic $\mathrm{Pd}-\mathrm{Ir} / \mathrm{TiO}_{2}$ catalyst. Catal Commun 24:38-43

[59] Mason MG, Gerenser LJ, Lee ST (1977) Electronic structure of catalytic metal clusters studied by X-ray photoemission spectroscopy. Phys Rev Lett 39:288-291

[60] Qiu L, Liu F, Zhao L, Yang W, Yao J (2006) Evidence of a unique electron donor-acceptor property for platinum nanoparticles as studied by XPS. Langmuir 22:4480-4482

[61] Ruban A, Hammer B, Stoltze P, Skriver HL, Norskov JK (1997) Surface electronic structure and reactivity of transition and noble metals. J Mol Catal A 115:421-429

[62] Goyhenex C, Piccolo L (2017) How the hydrogen sorption properties of palladium are modified through interaction with iridium. Phys Chem Chem Phys 19:32451-32458

[63] Shao MH, Huang T, Liu P, Zhang J, Sasaki K, Vukmirovic MB, Adzic RR (2006) Palladium monolayer and palladium alloy electrocatalysts for oxygen reduction. Langmuir 22:10409-10415

[64] Kibler LA, El-Aziz AM, Hoyer R, Kolb DM (2005) Tuning reaction rates by lateral strain in a palladium monolayer. Angew Chem Int Ed 44:2080-2084

[65] Hu S, Scudiero L, Ha S (2012) Electronic effect on oxidation of formic acid on supported $\mathrm{Pd}-\mathrm{Cu}$ bimetallic surface. Electrochim Acta 83:354-358

[66] Łukaszewski M, Klimek K, Zurowski A, Kẹdra T, Czerwiński A (2011) Kinetics and mechanism of hydrogen electrosorption in palladium-based alloys. Solid State Ionics 190:18-24

[67] Zhang HX, Wang C, Wang JY, Zhai JJ, Bin CW (2010) Carbon-supported Pd-Pt nanoalloy with low Pt content and superior catalysis for formic acid electro-oxidation. J Phys Chem C 114:6446-6451

[68] Łukaszewski M, Zurowski A, Grdeń M, Czerwiński A (2007) Correlations between hydrogen electrosorption properties and composition of Pd-noble metal alloys. Electrochem commun 9:671-676

[69] Zlotea C, Morfin F, Nguyen TS, Nguyen NT, Nelayah J, Ricolleau C, Latroche M, Piccolo L (2014) Nanoalloying bulk-immiscible iridium and palladium inhibits hydride formation and promotes catalytic performances. Nanoscale 6:9955-9959

[70] Ziemecki SB, Michel JB, Jones GA (1986) Hydride formation as a measure of alloying in bimetallic systems containing palladium. React Solids 2:187-202

[71] Rand DAJ, Woods R (1972) Determination of the surface composition of smooth noble metal alloys by cyclic voltammetry. J Electroanal Chem Interfacial Electrochem $36: 57-69$ 
[72] Łukaszewski M, Czerwiński A (2008) Selected electrochemical properties of $\mathrm{Pd}-\mathrm{Au}$ alloys: hydrogen absorption and surface oxidation. J Solid State Electrochem 12:15891598

[73] Simoes M, Baranton S, Coutanceau C (2009) Electrooxidation of sodium borohydride at $\mathrm{Pd}, \mathrm{Au}$ and $\mathrm{PdAu}$ carbonsupported nanocatalysts. J Phys Chem C 113:13369-13376

[74] Lankiang S, Chiwata M, Baranton S, Uchida H, Coutanceau C (2015) Oxygen reduction reaction at binary and ternary nanocatalysts based on $\mathrm{Pt}, \mathrm{Pd}$ and $\mathrm{Au}$. Electrochim Acta 182:131-142

[75] Yeo BS, Bell AT (2011) Enhanced activity of gold-supported cobalt oxide for the electrochemical evolution of oxygen. J Am Chem Soc 133:5587-5593

[76] Zhang L, Wan L, Ma Y, Chen Y, Zhou Y, Tang Y, Lu T (2013) Crystalline palladium-cobalt alloy nanoassemblies with enhanced activity and stability for the formic acid oxidation reaction. Appl Catal B Environ 138-139:229-235

[77] Paulus UA, Wokaun A, Scherer GC, Schmidt TJ, Stamenkovic V, Radmilovic V, Markovic NM, Ross PN (2002) Oxygen reduction on carbon-supported $\mathrm{Pt}-\mathrm{Ni}$ and $\mathrm{Pt}-\mathrm{Co}$ alloy catalysts. J Phys Chem B 106:4181-4191
[78] Bao J, Dou M, Liu H, Wang F, Liu J, Li Z, Ji J (2015) Composition-dependent electrocatalytic activity of palladium-iridium binary alloy nanoparticles supported on the multiwalled carbon nanotubes for the electro-oxidation of formic acid. ACS Appl Mater Interphases 7:15223-15229

[79] Hu S, Munoz F, Noborikawa J, Haan J, Scudiero L, Ha S (2016) Carbon supported Pd-based bimetallic and trimetallic catalyst for formic acid electrochemical oxidation. Appl Catal B Environ 180:758-765

[80] Nakagawa Y, Takada K, Tamura M, Tomishige K (2014) Total hydrogenation of furfural and 5-hydroxymethylfurfural over supported Pd-Ir alloy catalyst. ACS Catal 4:2718-2726

[81] Reyes P, Aguirre M, Melián-Cabrera I, López Granados M, Fierro JL (2002) Interfacial properties of an $\mathrm{Ir} / \mathrm{TiO}{ }_{2}$ system and their relevance in crotonaldehyde hydrogenation. J Catal 208:229-237

Publisher's Note Springer Nature remains neutral with regard to jurisdictional claims in published maps and institutional affiliations. 